Hydrocarbon Technologies, Inc. P.O. Box 6047

New York \& Puritan Avenues

Lawrenceville, New Jersey 08648

609/394-3102 Fax:609/394-9602

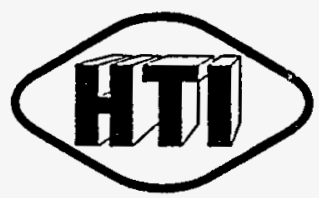

Alfred G. Comolli

President

95/AGC/181

October 10, 1995

Document Control Center

U.S. Department of Energy

Pittsburgh Energy Technology Center

P.O. Box 10940, MS 921-118

Pittsburgh, PA 15236-0940

Subject: DOE Contract No. DE-AC22-93PC92147

Attached are 10 copies of a final version of the Eleventh Quarterly Report for the subject contract covering the period 1 April - 30 June 1995. Please distribute per contract requirements.

Sincerely yours,

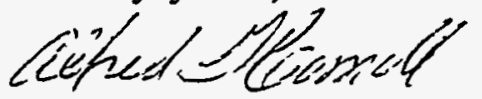

Alffed G. Comolli

Project Manager

$\mathrm{ACG} / \mathrm{jd}$

Enclosures 10

cc: Hugh Glenn - U.S. DOE

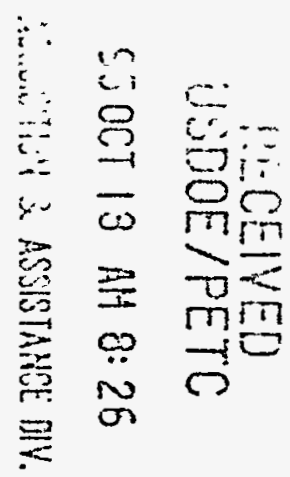

\title{
DISCLAIMER
}

This report was prepared as an account of work sponsored by an agency of the United States Government. Neither the United States Government nor any agency thereof, nor any of their employees, makes any warranty, express or implied, or assumes any legal liability or responsibility for the accuracy, completeness, or usefulness of any information, apparatus, product, or process disclosed, or represents that its use would not infringe privately owned rights. Reference herein to any specific commercial product, process, or service by trade name, trademark, manufacturer, or otherwise does not necessarily constitute or imply its endorsement, recommendation, or favoring by the United States Government or any agency thereof. The views and opinions of authors expressed herein do not necessarily state or reflect those of the United States Government or any agency thereor. 


\section{CATALYTIC MULTI-STAGE LIQUEFACTION OF COAL}

\section{ELEVENTH QUARTERLY REPORT FOR THE PERIOD}

\section{APRIL 1995 - 30 JUNE 1995}

A.G. Comolli

E.S. Johanson

L.K. Lee

V.R. Pradhan

R.H. Stalzer

FINAL

WORK PERFORMED UNDER CONTRACT

DE-AC22-93PC92147

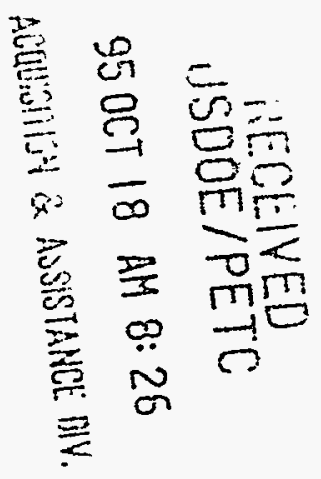

HYDROCARBON TECHNOLOGIES, INC. PO BOX 6047, NEW YORK \& PURITAN AVENUES

LAWRENCEVILLE, NJ 08648

OCTOBER 1995 
CATALYTIC MULTI-STAGE LIQUEFACTION OF COAL

ELEVENTH QUARTERLY REPORT FOR THE PERIOD

1 APRIL 1995 - 30 JUNE 1995

A.G. Comolli

E.S. Johanson

L.K. Lee

V.R. Pradhan

R.H. Stalzer

FINAL

WORK PERFORMED UNDER CONTRACT

DE-AC22-93PC92147

HYDROCARBON TECHNOLOGIES, INC.

PO BOX 6047, NEW YORK \& PURITAN AVENUES

LAWRENCEVILLE, NJ 08648

OCTOBER 1995 


\section{TABLE OF CONTENTS}

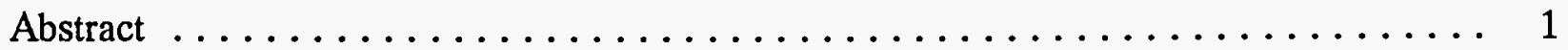

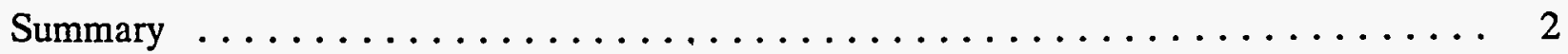

Task 2 - Laboratory Scale Studies ....................... 4

Task 3 - Bench-Scale Studies ......................... 5

Run CMSL-09 (227-87): Evaluation Of An All Dispersed Slurry

Catalyst Multi-Stage Back-Mixed Reactor System For Coal Liquefaction

And Coal/Waste Plastics Coprocessing $\ldots \ldots \ldots \ldots \ldots \ldots \ldots \ldots \ldots$

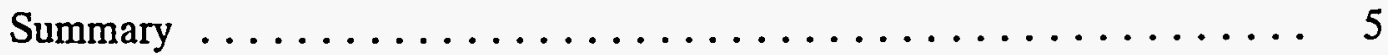

Background, Objective, And Scope Of Work $\ldots \ldots \ldots \ldots \ldots \ldots \ldots$

Operational Details ......................... 9

Recycle Solvent Balance $\ldots \ldots \ldots \ldots \ldots \ldots \ldots \ldots \ldots \ldots \ldots$

Process Performance ....................... 10

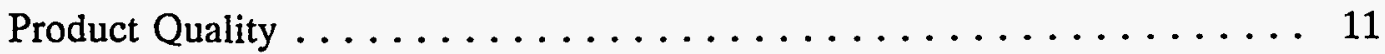

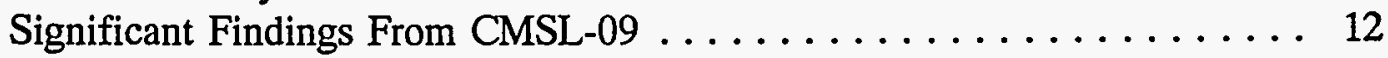

Interstage Samples . . . . . . . . . . . . . . . . . 15

External Samples . . . . . . . . . . . . . . . . . . 15

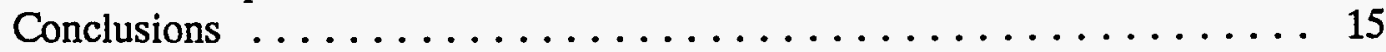

Run CMSL-10 (227-88): Evaluation Of A Combined Iron-Molybdenum Dispersed Slurry Catalyst System For Liquefaction Of Black Thunder

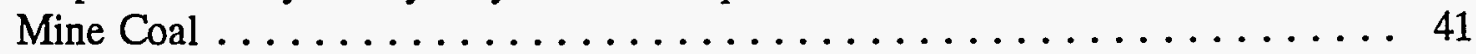

Summary ........................ 41

Background, Objective, And Scope Of Work ............ 42

Operational Details ....................... 44

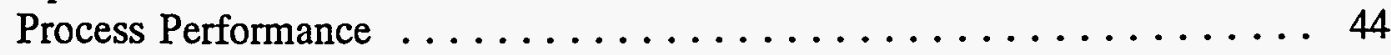

Product Quality . . . . . . . . . . . . . . . . . . 46

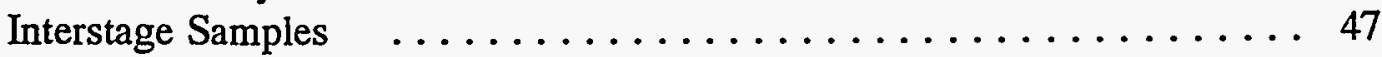

External Samples . . . . . . . . . . . . . . . . . . 47

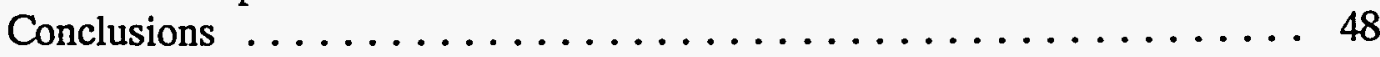

Recommendations For Future Work $\ldots \ldots \ldots \ldots \ldots \ldots \ldots \ldots$

Task 4- Technical Assessment . . . . . . . . . . . . . . . . . 70

Task 5- Project Management $\ldots \ldots \ldots \ldots \ldots \ldots \ldots \ldots \ldots \ldots \ldots \ldots \ldots \ldots \ldots$ 


\section{LIST OF TABLES}

Table 1 CMSL-09 Run Plan ....................... 17

Table 2 Analysis Of Coal And Plastic Feedstocks For CMSL-09 . . . . . . . 18

Table 3 Table 4 Analysis Of Start-Up/Make-Up Oil For CMSL-09 . . . . . . . . . . 19

Table 5 CMSL-09: Process Performance Summary . . . . . . . . . . 20

Table 6 Table 7 Hydrotreater Performance During CMSL-09 . . . . . . . . . . . 21 CMSL-09: Separator Overhead (SOH) Inspection $\ldots \ldots \ldots \ldots \ldots \ldots .22$

Table 8 Table 9 Table 10 Table 11 Table 12 Table 13 Table 14 Table 15 . Table 16 Table 17 Table 18 Table 19 Table 20 Table 21 CMSL-09: Atmospheric Still Overhead (ASOH) Inspection $\ldots \ldots \ldots \ldots 23$ CMSL-09: Properties Of Pressure Filter Liquids (Stage II) . . . . . . . 24 CMSL-09: Inspection Of Pressure Filter Solids (Stage II) $\ldots \ldots \ldots \ldots 25$ CMSL-09: Properties Of Pressure Filter Liquid (Stage I) $\ldots \ldots \ldots \ldots .26$ CMSL-09: Inspection Of Pressure Filter Solids (Stage 1 . . . . . . . 27

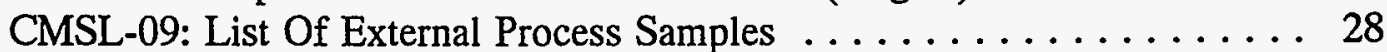
Comparison Between CMSL-09 Condition 6 And Exxon's Data . . . . . 29 CMSL 10 Run Plan . . . . . . . . . . . . . . . . . . 49 CMSL 10: Process Performance Summary ............. 50 CMSL 10: Separator Overhead (SOH) Properties . . . . . . . . . 51 CMSL 10: Properties Of Pressure Filter Liquid (Stage II) $\ldots \ldots \ldots \ldots 52$ CMSL 10: Inspection Of Pressure Filter Solid (Stage II) $\ldots \ldots \ldots \ldots 53$

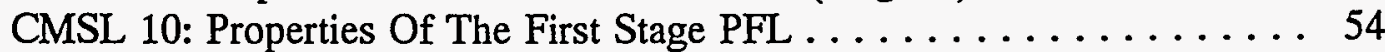
CMSL 10: Inspection Of The First Stage PFS $\ldots \ldots \ldots \ldots \ldots \ldots \ldots 5$ CMSL 10: List Of External Process Samples $\ldots \ldots \ldots \ldots \ldots \ldots \ldots 56$ 


\section{LIST OF FIGURES}

Figure 1 - CMSL 09: Simplified Schematic Of Bench Unit Configuration . . . . . . 30

Figure 2 - CMSL 09: Reactor Temperatures ................... 31

Figure 3 - CMSL 09: Operating Conditions $\ldots \ldots \ldots \ldots \ldots \ldots \ldots \ldots \ldots \ldots \ldots \ldots \ldots$

Figure 4 - CMSL 09: Daily Material Balance $\ldots \ldots \ldots \ldots \ldots \ldots \ldots \ldots \ldots \ldots$

Figure 5 - CMSL 09: Recycle Solvent Balance ................. 34

Figure 6 - CMSL 09: Feed And Resid Conversions $\ldots \ldots \ldots \ldots \ldots \ldots \ldots \ldots$

Figure 7 - CMSL 09: $\mathrm{C4}-524^{\circ} \mathrm{C}$ Distillate Yields ............... 36

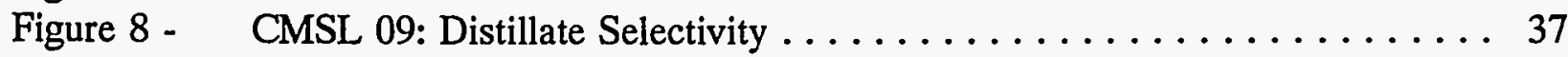

Figure 9 - CMSL 09: Yields On Dry Feed Basis $\ldots \ldots \ldots \ldots \ldots \ldots \ldots \ldots$

Figure 10 - CMSL 09: SOH Distillate Quality .................. 39

Figure 11 - CMSL 09: Estimated HDPE Conversion ............... 40

Figure 12 - CMSL 10: Simplified Schematic Of Bench Unit Configuration . . . . . . . 57

Figure 13 - CMSL 10: Daily Material Balance ................. 58

Figure 14 - CMSL 10: Operating Conditions .................. 59

Figure 15 - CMSL 10: Catalyst Loading vs. Conditions $\ldots \ldots \ldots \ldots \ldots \ldots \ldots 60$

Figure 16 - CMSL 10: Feed Coal Conversions ................. 61

Figure 17 - CMSL 10: Total $524^{\circ} \mathrm{C}+$ Resid Conversions . . . . . . . . . . . . 62

Figure 18 - CMSL 10: $\mathrm{C} 4-524^{\circ} \mathrm{C}$ Distillate Yields $\ldots \ldots \ldots \ldots \ldots \ldots \ldots \ldots \ldots \ldots$

Figure 19 - CMSL 10: Distillate Selectivity ................... 64

Figure 20 - CMSL 10: Chemical Hydrogen Consumption ............. 65

Figure 21 - CMSL 10: Light C1-C3 Gas Yield .................. 66

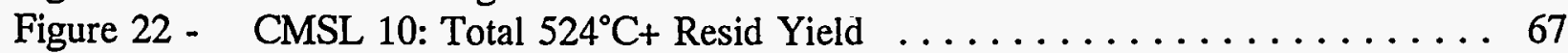

Figure 23 - CMSL 10: Solubility Of PFL Product $\ldots \ldots \ldots \ldots \ldots \ldots \ldots \ldots 6$

Figure 24 - CMSL 10: SOH Distillate Quality . . . . . . . . . . . . . . 69 


\begin{abstract}
This quarterly report covers the activities of Catalytic Multi-Stage Liquefaction of Coal during the Period April 1 - June 30, 1995, at Hydrocarbon Technologies, Inc. in Lawrenceville, New Jersey. This DOE Contract Period was from December 8, 1992 to December 7, 1994 and has been extended to September 30, 1995.

The overall objective of this program is to produce liquid fueis from coal by direct liquefaction at a cost that is competitive with conventional fuels. Specifically, this continuous bench-scale program contains provisions to examine new ideas in areas such as: low temperature pretreatments, more effective catalysts, on-line hydrotreating, new coal feedstocks, other hydrogen sources, more concentrated coal feeds and other highly responsive process improvements while assessing the design and economics of the bench-scale results.

This quarterly report covers work on Laboratory Scale Studies, Continuous Bench-Scale Operations, Technical Assessment and Project Management.
\end{abstract}




\section{SUMMARY}

This report describes the following: i) continuous bench-scale operations for Run CMSL-09 and ii) continuous bench-scale operations for Run CMSL-10.

Bench run CMSL-09 was a unique bench operation in that for the first time at HTI, a 41- day long continuous operation was carried out in an all-dispersed catalyst multi-stage reactor configuration. Similar to Run CMSL-08, an in-line hydrotreater was employed to lower the heteroatom content of the distillates. The overall operation was spread over nine run conditions. The effects of two dispersed catalysts, Molyvan-A, a cheap source of molybdenum, and HTI's iron catalyst, in their fresh as well as recycled forms, were studied for the multistage liquefaction of Wyoming Black Thunder Mine subbituminous coal. The last three conditions, spread over 12 operating days, also investigated coal/plastics coprocessing under steady-state recycle solventbalanced conditions. During this time, effects of having 33 and $50 \mathrm{w} \%$ mixed plastics in the feed with coal were studied (mixed plastics were $40 \% \mathrm{HDPE}, 33 \% \mathrm{PP}$, and 27\% PS); one of the conditions also looked at the coprocessing of HDPE alone @ 33 w\% with coal. Since dispersed catalysts were the only catalysts used in the reactors, a high feed throughput corresponding to a space velocity of $640 \mathrm{~kg} \mathrm{coal} / \mathrm{hr} / \mathrm{m}^{3}$ reactor volume could be maintained.

CMSL-09 was a very successful bench run from a technical, as well as an operational, standpoint. A net positive solvent balance (excess production of $343^{\circ} \mathrm{C}+$ oil over what is needed for recycle) was obtained for all the operating periods of this bench run. Over 41 days of continuous operation (12 days on coal/plastics coprocessing) were completed during CMSL-09 without any major interruptions. Samples of different process streams were also obtained for Consol, Inc. for property characterization/assessment. This bench run not only succeeded in providing insights into combined processing of coal with MSW plastics but also indicated the type of reaction severity, reactor configuration, and catalysts needed for achieving near-optimum process performance. So far as the effect of dispersed catalysts was concerned, it was once again observed that the molybdenum catalyst, freshly added as Molyvan-A precursor, is not as active in the recycled form as the freshly added form. The use of an in-line hydrotreater allows one the luxury of not having to use expensive supported metal extrudate catalysts in the liquefaction/coprocessing reactors. As long as the alternative dispersed slurry catalysts are cheap and effective for coal and resid conversions under the given process severity, the finishing of the light distillates to remove heteroatoms and to add more hydrogen can be achieved by an in-line hydrotreater.

Bench Run CMSL-10 (HTI Run 227-88) was designed as a follow-up study after the operation of Bench Run CMSL-09. During CMSL-09, for the first time at HTI, an all dispersed (slurry) catalyst reactor system was used for coal liquefaction and coal/waste plastics coprocessing. Interestingly, the performance of a multi-stage coal liquefaction unit, under a suitable reaction severity and with an in-line hydrotreater, was found to exceed the earlier process performance using ebullated bed reactors with supported catalysts. This result was very significant, as dispersed slurry catalysts, based on iron and molybdenum, employed during CMSL-09, are not only more economical to use than the supported catalysts, but they also have a tremendous potential to lower the overall operational costs for coal liquefaction by virtue of elimination of 
the expensive ebullated bed reactors from the system. The effects of individual iron-based HTI properietery catalyst and molybdenum, added as Molyvan-A, were not fully understood during CMSL-09. One of the main objectives of run CMSL-10 was to further understanding of the effects of iron and molybdenum employed alone and added together. The mode of addition of HTI's iron catalyst and overall process severity (reactor temperatures and space velocity) were among the variables studied during CMSL-10.

After 18 periods of continuous operation, CMSL-10 was successfully completed with one brief shut-down. The results demonstrated that the combined system of $\mathrm{Mo}$ and $\mathrm{FeOOH}$ type catalysts improved process performance (iron alone was not very effective a catalyst). It was discovered that process performance remained the same even though iron catalyst $\left(\mathrm{FeOOH} / \mathrm{SO}_{4}\right)$ was added as wet cake containing $70 \mathrm{~W} \%$ water. This discovery has led to the further reduction on the catalyst cost by $30 \%$ due to the elimination of two time consuming/expensive processing steps in catalyst preparation. The space velocity and catalysts had an impact on the $524^{\circ} \mathrm{C}+$ conversion and distillate yield but did not seem to affect the total conversion. A slight change of the qualities of SOH and PFL was observed upon changing space velocity. This suggests that the current process can be operated at even higher throughput. The in-line hydrotreating was very effective for the removal of heteroatoms and for hydrogenation. The use of an in-line hydrotreatior has resulted in the production of quality distillates which contain less than $50 \mathrm{ppm}$ each of sulfur and nitrogen. The analysis of the qualities of samples from different process streams indicate that the current reactor configuration and combined system of Mo and $\mathrm{Fe}$ catalysts are effective in producing quality products from coal liquefaction. It is possible to establish a near-optimum process for coal liquefaction using a suitable combination of iron and molybdenum in low concentrations ( $5000 \mathrm{ppm}$ for iron and $50-100 \mathrm{ppm}$ for molybdenum) so that these dispersed catalysts can be employed on a disposable basis. 


\section{TASK 2 - LABORATORY SCALE STUDIES}

No laboratory support work was conducted during this reporting period except for the analyses of the feeds and products from bench operations CMSL-09 and CMSL-10. These are discussed in the section on Bench-Scale Studies. 


\title{
TASK 3 - BENCH-SCALE STUDIES
}

\author{
RUN CMSL-09 (227-87)
}

\section{EVALUATION OF AN ALL DISPERSED SLURRY CATALYST MULTI-STAGE BACK-MIXED REACTOR SYSTEM FOR COAL LIQUEFACTION AND COAL/WASTE PLASTICS COPROCESSING}

\section{SUMMARY}

Bench run CMSL-09 was a unique bench operation in that for the first time at HTI, a 41 day long continuous operation was carried out in an all-dispersed catalyst multi-stage reactor configuration. Similar to Run CMSL-08, an in-line hydrotreater was employed to lower the heteroatom content of the distillates. The overall operation was spread over nine run conditions. The effects of two dispersed catalysts, Molyvan-A, a cheap source of molybdenum, and HTT's iron catalyst, in their fresh as well as recycled forms, were studied for the multistage liquefaction of Wyoming Black Thunder Mine subbituminous coal. The last three conditions, spread over 12 operating days, also investigated coal/plastics coprocessing under steady-state recycle solventbalanced conditions. During this time, effects of having 33 and $50 \mathrm{w} \%$ mixed plastics in the feed with coal were studied (mixed plastics were 40\% HDPE, 33\% PP, and 27\% PS); one of the conditions also looked at the coprocessing of HDPE alone @ 33 w\% with coal. Since dispersed catalysts were the only catalysts used in the reactors, a high feed throughput corresponding to a space velocity of $640 \mathrm{~kg} \mathrm{coal} / \mathrm{hr} / \mathrm{m}^{3}$ reactor volume could be maintained.

The best performance for the 'coal-only' periods of CMSL-09 was obtained for Condition 1, Period 5. The resid conversion of about $92 \%$ and distillate yield of about $67 \%$ (both maf) were obtained at the process conditions shown and for $300 \mathrm{ppm}$ of Mo, added as Molyvan- $\mathrm{A}$, to the feed slurry. The overall process performance degraded in going from Condition 1 to 3 and then 4, i.e., in going from $300 \mathrm{ppm}$ fresh Mo, to a combination of $150 \mathrm{ppm}$ fresh and $150 \mathrm{ppm}$ recycled $\mathrm{Mo}$, and then to $300 \mathrm{ppm}$ recycled Mo catalyst. The resid conversion during these transitions dropped by as much as $8 \%$, while distillate yield decreased by $7 \%$ (both maf absolute bases). This trend in process performance confirms that molybdenum, in the recycled form, is not quite as active as fresh molybdenum, although this does not rule out that recycled molybdenum may possess some catalytic activity. Coal conversions, based upon quinoline solubility of the products, were uniform, at around 95-96 \% maf throughout the 'coal-only' conditions, except for Condition 4 with all recycled Mo catalyst, when it decreased to $92.8 \%$ maf. Overall chemical hydrogen consumption varied between 6-7.5\% maf. The $\mathrm{C}_{1}-\mathrm{C}_{3}$ gas make varied between 10$11.5 \%$ maf coal.

The coal/plastics coprocessing operations during the last 12 days of CMSL-09 were successful in that Condition 7, Period 34, which coprocessed 33\% mixed plastics with coal, gave as high as $75.4 \%$ distillate yield with over $92 \%$ (both maf bases) resid conversion. For Condition 8 , Period 38, with 33\% HDPE alone and $67 \%$ coal in the feed, the performance was poor (61\% maf distillate yield and $79 \%$ maf resid conversion), confirming the poor reactivity of HDPE that was found during CMSL-08. Switching back to mixed plastics at 50\% of total feed during Condition 9, Period 41, overall process performance jumped back to yield as high $75 \%$ distillates 
and $88 \%$ resid conversion (maf). During Conditions 7 and 9 with mixed plastics much improved process performance over the earlier 'coal-only' conditions was obtained at a much reduced gasmake (7.5-8.5\% maf) and lower chemical hydrogen consumption (3.5 to 5\% maf). Thus, the coal/plastics coprocessing operations from both CMSL-09 and CMSL-08 resulted in improved overall process performance with better hydrogen utilization. This, we feel, will certainly improve the overall economics of coal conversion besides adding to it an environmental aspect.

The separator overhead oil products from CMSL-09 represent the net light distillate stream from the process. The overhead stream, which is essentially the liquids boiling between an initial boiling point of about $60^{\circ} \mathrm{C}$ and $370^{\circ} \mathrm{C}$, represents a combination of hot separator (O-1) overhead and continuous atmospheric still (N-1 CAS) overhead streams which passed through the in-line hydrotreating unit, $\mathrm{K}-3$. The product stream from $\mathrm{K}-3$ is designated as the overall $\mathrm{SOH}$ (Separator OverHead) product. The other part of the distillate comes from the IBP to $524^{\circ} \mathrm{C}$ boiling fraction of the pressure filter liquid (PFL) or the vacuum still overheads (VSOH), which are used to constitute recycle solvent, depending upon what is used for solid separation of the CAS bottoms. The API gravities and H/C atomic ratios of the SOH oil from CMSL-09 have been high (35-43, and 1.73-1.82 respectively), especially for the coal/plastics coprocessing conditions. The quality of the distillates is also premium.The API gravities (an indication of paraffinic character) of the distillate increased significantly in going from the 'coal-only' conditions to 'coal/plastics' conditions (from about 32-37 to 40-44). The $\mathrm{H} / \mathrm{C}$ ratios also improved during the transition. The light boiling naphtha (IBP- $177^{\circ} \mathrm{C}$ ) fraction increased significantly during the coprocessing conditions, except for the condition that coprocessed coal with HDPE alone, instead of mixed plastics. The sulfur and nitrogen contents of the distillate products were very low in general (10-100 ppm) and were even lower for the coal/plastics coprocessing conditions.

Overall process performance, using plastics in the feed with both coals independently, was much better with improved hydrogen utilization, a significant benefit one strives to derive from the plastics part of the feed in such coprocessing. Secondly, more so with a subbituminous coal (CMSL-09), it was found that plastics had a synergistic effect on coal conversion in terms of improving the $\mathrm{C}_{4}-524^{\circ} \mathrm{C}$ premium distillate yield. It was also learned that reactivity of HDPE, a hard-to-convert polymer, is improved under coal liquefaction conditions when other polymers such as polypropylene and polystyrene are present. This conclusion is based upon estimations of individual coal and plastics conversions to $524^{\circ} \mathrm{C}$ - material under reaction conditions. If it is assumed that $88-90 \%$ coal resid conversion is obtained along with complete conversions of both polypropylene and polystyrene, the conversion of HDPE in the presence of other polymers is about $12-35 \%$ higher than when HDPE is coprocessed alone with coal. Indeed, it is strongly believed that, because of all the positive effects of an all dispersed slurry catalyst reactor configuration and coprocessing waste plastics with coal, the economics of coal liquefaction will improve significantly. More importantly, such coprocessing technology would allow reuse of a very valuable hydrocarbon source (waste plastics) into the energy stream in an environmentally benign manner. 


\section{BACKGROUND, OBJECTIVE, AND SCOPE OF WORK}

Bench Run CMSL-09 was carried out using a dispersed catalyst-only two-stage, back-mixed reactor system. The two-stage conversion reactors were preceded by back-mixed pre-treatment reactor at lower temperature and half the capacity (volume) of each of the conversion reactors. The pretreatment reactor was intended for sulfidation of the dispersed catalyst additive. Bench run CMSL-09 was forty one days long, comprising nine operating conditions (3-5 days each). The objectives of this bench operation were:

- To determine the process performance for subbituminous coal liquefaction using a threestage (including pretreater) dispersed catalyst-only back-mixed reactor system.

- To investigate the effect of molybdenum additive concentration on overall process performance.

- To determine the activity of fresh molybdenum catalyst vs. recycled moly catalyst.

- To study the effect of iron additive (in the presence of molybdenum), $\mathrm{FeOOH} / \mathrm{SO}_{4}$, on process performance.

- To obtain a tie-point, for process performance comparisons, with reference to Exxon's latest coal liquefaction run using dispersed Fe/Mo catalysts, RCLU 1, Condition 4 (Yield Periods 422-424).

- To obtain performance data on plastics and coal coprocessing for variable feed compositions and at higher severity and in a dispersed catalyst-only system.

An in-line hydrotreater was used during this run. Both the hot separator (O-1) overheads and the atmosheric still overheads (ASOH) were sent through the hydrotreater. In order to obtain distillate samples that are not hydrotreated and to arrive at a mass-balance around hydrotreater, the HTU was bypassed during a few operating periods of the run.

The Run Plan (Table 1) included nine run conditions that were selected to meet the technical objectives specified above. By not using a supported extrudate catalyst in any of the coal liquefaction reactors, it became possible to compare the process performance of different run conditions on a one-to-one basis without being affected by 'catalyst batch-deactivation' phenomenon typical of bench CTSL operations. For the first five run conditions, 1 through 5, reactor temperatures and feed space velocities were maintained constant. These conditions studied the effects of varying the addition rate of molybdenum precursor and the relative activities of fresh vs. recycled moly catalyst. It is expected that molybdenum exists as $\mathrm{MoS}_{\mathrm{x}}$ in the recycled solids (ash, char, and unconverted coal). Condition 5 studied the effect of adding $\mathrm{FeOOH} / \mathrm{SO}_{4}$ precursor/catalyst on overall process performance. 
Condition 6 simulated the same operating conditions as those employed during Condition 4 (Yield Periods 422-424) of Exxon's RCLU Dispersed Slurry Catalyst Run 1. The objective was to obtain a tie-point for process performance comparison. Conditions 7 through 9 studied the combined processing of coal and plastics at different feed compositions and higher reactor temperatures than 'coal-only' Conditions 1 through 6.

Conditions 7 through 9 were designed to further our understanding of coal and waste plastics coprocessing using subbituminous coal and different feed compositions (w\% plastics in feed), in an all dispersed catalyst reaction system. Mixed plastics (40\% HDPE, 33\% PP, and 27\% PS) were used with coal at 33 and $50 \mathrm{w} \%$ feed composition during Conditions 7 and 9 respectively. The Condition 8 studied the effect of coprocessing $33 \mathrm{w} \% \mathrm{HDPE}$ (a single plastic) in feed with coal, on the overall process performance.

\section{SYSTEM CONFIGURATION:}

CMSL-09 involved two equal volume backmixed reactors, a one half volume $(1000 \mathrm{cc})$ pretreatment vessel (also back-mixed), and a fixed-bed hydrotreater. High pressure slurry samples were obtained both after the pretreatment vessel and after the first conversion reactor. The simplified schematic of this configuration is shown in Figure 1.

The reactors from existing units 227 and 238 were used in this run with the necessary re-piping and equipment modifications. A hot-slurry mix tank system was used throughout the run for slurry preparation. No supported catalyst was used in any of the conversion reactors, except in the hydrotreater (HTU). Hydrogen sulfide $\left(\mathrm{H}_{2} \mathrm{~S}\right)$, as a source of sulfur for the activation of dispersed iron and molybdenum additives, was continually added to the pretreater at $3 \mathrm{w} \%$ of dry coal.

\section{COAL FEED AND WASTE PLASTICS}

A subbituminous Black Thunder Mine Coal (HRI-6213), the same coal that was used in PDU 260-005 (POC-02 Run) operations, was used for the CMSL-09 (227-87) bench run. The waste plastics stream was simulated by using pure resins, such as HDPE, PS, and PP, in an extrudate form, co-mingled in the proportions representative of MSW plastics. The analyses of the coal and plastics are given in Table 2.

\section{START-UP AND MAKE-UP OIL}

Tank 4 material was L-814, a combination of hydrotreated petroleum-derived oil with small amounts of coal-derived liquid obtained during the operations of POC-02 PDU Run (Table 3). 


\section{CATALYST}

Hydrotreater:

Pretreater (carried over to K-1 and K-2):

Criterion C-411 Trilobe (HRI-6135)

Molyvan- $\mathrm{A}, \mathrm{FeOOH} / \mathrm{SO}_{4}$, and $3 \%$ $\mathrm{H}_{2} \mathrm{~S}$ relative to dry coal.

The dispersed acidic catalyst, $\mathrm{FeOOH} / \mathrm{SO}_{4}$, was synthesized by aqueous precipitation in a solution containing sulfate anions. Molybdenum, or Molyvan-A, was obtained from R.T. Vanderbilt \& Co.

\section{RECYCLED-DISPERSED CATALYST}

Oil-free pressure filter cake, extracted with toluene, was used as the source of the recycleddispersed catalyst. The extracted filter cakes were dried to remove any residual solvent (toluene) and analyzed for molybdenum. Based on this analysis, the flowrate of the dried, extracted filter cake to the feed slurry was determined.

\section{OPERATIONAL DETAIS}

An average material balance of $99.25 \mathrm{~W} \%$ was obtained (Figure 4) for the entire Bench Run CMSL-09. The operating summary of individual periods during CMSL-09 is shown in Table 4. Figures 2 and 3 show the operating conditions during CMSL-09 in terms of coal space velocity reactor temperatures, and feed pot (slurry mix tank) temperature. As shown in these figures, the pretreater and reactor temperatures are close to their desired values, and space velocities held at $640 \mathrm{~kg} / \mathrm{h} / \mathrm{m}^{3}$ reactor throughout the run. It can also be seen in Figure 3 that due to the increased viscosity of feed, the slurry mix tank temperature had to be progressively increased to maintain the pumpability.

\section{RECYCLE SOLVENT BALANCE}

One of the primary objectives of CMSL- 09 was to investigate the dispersed catalyst catalyzed direct coal liquefaction and coal/waste plastics coprocessing under steady-state or equilibrated process conditions. An important factor in such processing is the net recycle solvent/oil balance. This has to be positive to ensure that no external make-up oil is needed for slurry preparation, as the use of make-up oil would cloud the interpretation of the reaction data. It was feared that plastics, under typical coal liquefaction conditions, would result in substantial formations of light oils and a shortage of heavy recycle oil $\left(399^{\circ} \mathrm{C}+\right.$ material) would result. As shown in Figure 5, this was not the case. A net positive solvent balance was achieved almost throughout the entire run. 


\section{PROCESS PERFORMANCE}

\section{TOTAL FEED (COAL+PLASTICS) CONVERSION}

Typical feed conversions (based on the solubility of pressure filter solids or vacuum still bottoms in quinoline) obtained during equilibrated periods of different conditions of CMSL-09 are shown in Figure 6. The feed conversion (W\% maf feed) varied beween 95-97\% maf throughout the course of the run. Variations in the type and amount of dispersed catalyst additives did not seem to affect conversions significantly; presence of plastics in the feed also did not bring about any significant changes in overall feed conversion.

\section{C+ RESIDUUM CONVERSION}

Residuum conversion values varied between 79 to $92 \mathrm{~W} \%$ (maf feed) and were more sensitive to the type and amount of the dispersed catalyst precursor added to the feed, as shown in Figure 6. Resid conversion levels were not significantly different for 200 and $300 \mathrm{ppm}$ Mo added to the feed as Molyvan-A. Conversions dropped by about 6-7\% maf when $300 \mathrm{ppm}$ of Mo was used in the recycled-only form (by the addition of dried pressure filter cake). Resid conversion levels rose again as the iron catalyst was added to the feed with Molyvan-A and finally when the overall process severity was increased during the coal/plastics coprocessing operations. Similar to the observation made during CMSL-08, resid conversion during the coal+HDPE condition was the lowest (78.7\% maf), attesting to the conclusion that when HDPE is reacted individually with coal (without other plastics being present), it is difficult to convert to $524^{\circ} \mathrm{C}$ - material.

\section{$C_{4} 524^{\circ} \mathrm{C}$ DISTILLATE YIELDS AND SELECTIVITY}

Distillate yields, shown in Figure 7, followed a similar trend in going from Condition 1 to 9 as did resid conversion. In general, the yields varied between about $60 \%$ to about $75 \%$ maf during CMSL-09. For the coal-only conditions, the highest yield was obtained for Condition $1,66.6 \%$ maf. During the coal/plastics coprocessing operations, a very high distillate yield of over $75 \%$ maf was obtained when $33 \%$ mixed plastics were processed with coal. High yields were maintained when the mixed plastics concentration in the feed was increased to $50 \%$. Once again, as was the case during CMSL-08, distillate yields plummeted to about $61 \%$ from $75 \%$ when HDPE alone at $33 \%$ was coprocessed with coal.

So far as the selectivities of different boiling fractions of the net $\mathrm{C}_{4}-524^{\circ} \mathrm{C}$ distillate are concerned, the coal-only conditions resulted in $20-34 \%$ selectivity for the naphtha $\left(\mathrm{C}_{4}-177^{\circ} \mathrm{C}\right)$. This selectivity increased to about $40 \%$ during the coal/plastics coprocessing operations. Selectivity for middle distillates $\left(177-343^{\circ} \mathrm{C}\right)$ varied only slightly for the different run conditions. Selectivity for heavy distillate $\left(343-524^{\circ} \mathrm{C}\right)$ was the highest for Condition 8 , which coprocessed HDPE alone with coal. Thus, Condition 8 resulted not only in poor total distillate yields but also in poor selectivity to light boiling fractions. 


\section{HYDROGEN CONSUMPTION}

Hydrogen consumption (Figure 9) based on mf feed varied between 3.4 to 7.2 W\%. During the 'coal-only' conditions, no specific trend or pattern was seen in hydrogen consumption with respect to variation in the type and the amount of dispersed catalyst. As expected, chemical hydrogen consumption decreased in going from the coal-only operating periods to the coal/mixed plastics coprocessing periods. This was due to lower light gas make during co-liquefaction operations and higher chemical hydrogen content of the combined feed. As the $\mathrm{C}_{4}-524^{\circ} \mathrm{C}$ distillate yield increased significantly in going from the 'coal-only' conditions to the coprocessing conditions, the hydrogen efficiency or utilization during coal/plastics operation is much better than 'coal-only' operation.

\section{$C_{I^{-}-C_{3}}$ GAS YIELDS}

As shown in Figure 9 and Table 4, normalized $\mathrm{C}_{1}-\mathrm{C}_{3}$ gas yields for CMSL-09 varied between 7.3 to $12.1 \mathrm{~W} \% \mathrm{mf}$ feed. Light gas yield was highest $(12.1 \mathrm{~W} \%)$ during the coal-only operation of Condition 3, and decreased significantly during coal/plastics co-liquefaction operations (Condition 7 through 9). The lowest gas yield was obtained during the last run condition which was with $50 \%$ mixed plastics and coal. These findings indicate that mixed plastics do not form as much light hydrocarbon gas as the subbituminous coal feed.

\section{$524^{\circ} \mathrm{C}+\mathrm{RESIDUUM}$ YIELD}

Residuum yield (Figure 9) was between about $4 \%$ to about $16 \% \mathrm{mf}$ feed during CMSL-09. During the 'coal-only' conditions, residuum yield increased slowly as the amount of freshly added Mo catalyst was reduced from $300 \mathrm{ppm}$. Yields dropped when iron catalyst was added along with Molyvan-A. During coprocessing conditions, the highest resid yield was obtained for the Condition 8, which employed HDPE alone with coal. This observation also substantiates the refractory nature of HDPE towards conversion to light liquids and gases when coprocessed with coal, without any other plastics.

\section{PRODUCT QUALTTY}

Different product fractions (First-Stage/Second-Stage Vent Gases, CAS Bottoms, SOH, ASOH, PFL, VSOH and PFS/VSB) from Work-up Periods 5, 9, 15, 19, 24, 29, 34, 38, and 41 were analyzed in detail. These analyses for different product fractions are listed in Tables 6 through 11.

\section{Separator Overhead Product (SOH) and Atmospheric Still Overhead Product (ASOH)}

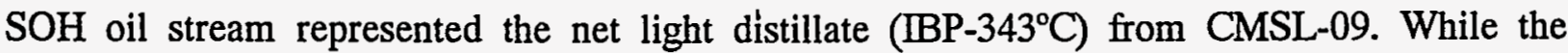
hydrotreater was on-line during the run, the only major distillate stream out of the unit was SOH, as $\mathrm{O}-1$ hot separator overheads, ASOH, and unit knockouts were being fed directly to the 
hydrotreater. The properties of $\mathrm{SOH}$ oil for the work-up periods are shown in Table 6 . The $\mathrm{SOH}$ oils had a typical boiling range of $54-399^{\circ} \mathrm{C}$. The API gravities were high ( $>35$ ), and $\mathrm{H} / \mathrm{C}$ atomic ratios were also high (1.73-1.82), especially during coal-plastics coprocessing. The yield of IBP $-177^{\circ} \mathrm{C}$, the lightest fraction of the $\mathrm{SOH}$-oil, was also higher during co-liquefaction than for coal-only Condition 1 . Heteroatom (nitrogen and sulfur) levels were low throughout the run, indicating very successful operation of the in-line hydrotreater. Typically, sulfur levels below $15 \mathrm{ppm}$ and nitrogen levels below $50 \mathrm{ppm}$ were obtained for the SOH oil. (It is believed that during Periods 24 and 29, the quality of the SOH oil stream was affected by a residual effect of bypassing of the HTU during Periods 23 and 28.)

The ASOH stream is obtained from the unit as a sample stream only. As seen from Table 7, this unhydrotreated oil stream has a low API gravity (4-14) except during coprocessing. The quality is also poor , i.e., high sulfur (200-375 ppm) and nitrogen (150-741 ppm) contents and low H/C atomic ratios (1.17-1.53). This stream, combined with the hot separator overheads (O-1) and unit knockouts, goes to the in-line hydrotreater for finishing.

The separator overhead oil from CMSL-09 represent the net light distillate stream from the process. The overhead stream, which is essentially the liquids boiling between about $60^{\circ} \mathrm{C}$ and $370^{\circ} \mathrm{C}$, represents a combination of the hot separator (O-1) overhead and the continuous atmospheric still (N-1 CAS) overhead streams which passes through in-line hydrotreating unit, $\mathrm{K}-3$. The product stream from $\mathrm{K}-3$ is designated as overall SOH (Separator OverHead) product. The other part of the distillate comes from the IBP to $524^{\circ} \mathrm{C}$ boiling fraction of the pressure filter liquid (PFL) or the vacuum still overheads (VSOH), which are used to constitute recycle solvent, depending upon what process is used for solid separation of the CAS bottoms. The API gravities and $\mathrm{H} / \mathrm{C}$ atomic ratios of the SOH oil from CMSL-09 are high (35-43, and 1.73-1.82 respectively), especially for the coal/plastics coprocessing conditions. The quality of the distillates is also premium.The API gravity (an indication of paraffinic character) of the distillate increased significantly (from about 32-37 to 40-44) in going from 'coal-only' conditions to 'coal/plastics' conditions. The $\mathrm{H} / \mathrm{C}$ ratios also improved during the transition. The light boiling naphtha (IBP$177^{\circ} \mathrm{C}$ ) fraction increased significantly during the coprocessing conditions, except for the condition that coprocessed coal with HDPE alone. The sulfur and nitrogen contents of the distillate products are very low in general (10-100 ppm), and even lower for the coal/plastics coprocessing conditions.

\section{SIGNIFICANT FINDINGS FROM CMSL-09}

\section{(I) Effect of Type and Amount of Dispersed Catalyst}

One of the objectives of CMSL-09 was to investigate the effect of dispersed molybdenum and iron catalysts on process performance. Four molybdenum concentrations were studied: $300 \mathrm{ppm}$ fresh, $200 \mathrm{ppm}$ fresh, $150 \mathrm{ppm}$ fresh plus $150 \mathrm{ppm}$ recycle, and $300 \mathrm{ppm}$ recycle-only. It was observed, under equivalent process severity conditions, that the molybdenum catalyst in freshly added precursor form was more active for coal residuum conversion than recycled molybdenum catalyst. Addition of $1 \mathrm{w} \%$ iron catalyst $\left(\mathrm{FeOOH} / \mathrm{SO}_{4}\right)$ during Condition 6 was found to improve 
the overall process performance slightly over Condition 5 (which used $150 \mathrm{ppm}$ fresh Mo and $150 \mathrm{ppm}$ recycled Mo). The source of the recycled catalyst in most cases was the Continuous Atmospheric Bottoms (CAS Bottoms) stream; during Condition 4, which was with $300 \mathrm{ppm}$ recycled-only Mo catalyst, a dried and toluene-extracted pressure filter cake, derived from the earlier periods of the run, had to be used. The observation made during this run on the relative activities of fresh vs. recycled Mo catalysts is consistent with what was seen with sulfated iron oxide catalyst during an earlier bench run, CMSL-06. As part of the follow-up of this finding, a few microautoclave batch tests are being planned to study the catalytic behavior of both fresh Molyvan-A and the dried pressure filter cakes from CMSL-09.

\section{(II) Effects of Feed Composition:}

The first six conditions during CMSL-09 were 'coal-only' feed conditions. It was during the last three conditions that coal/plastics coprocessing was carried out. The coal/plastics coprocessing operations during the last 12 days of CMSL-09 were successful in that during Condition 7, Period 34 , which coprocessed $33 \%$ mixed plastics with coal, as high as $75.4 \%$ distillate yield was obtained with over $92 \%$ (both maf bases) resid conversion. Next, for Condition 8 , Period 38, with $33 \% \mathrm{HDPE}$ alone and $67 \%$ coal in the feed, the performance was poor (61\% maf distillate yield and $79 \%$ maf resid conversion), confirming the poor reactivity of HDPE that was found during CMSL-08. Switching back to mixed plastics, at 50\% of total feed during Condition 9, Period 41, overall process performance jumped back to as high as $75 \%$ distillates and $88 \%$ resid conversion (maf). During Conditions 7 and 9, with mixed plastics, much improved process performance over the earlier 'coal-only' conditions was obtained at a much reduced gas-make (7.5-8.5\% maf) and lower chemical hydrogen consumption ( 3.5 to $5 \%$ maf).

\section{(III) Hydrotreater Performance:}

The in-line hydrotreater has performed well during CMSL-09, as exemplified by the low heteroatom contents of the distillate products and their high $\mathrm{H} / \mathrm{C}$ ratios. The absolute $\mathrm{N}$ and $\mathrm{S}$ contents are not as low as those obtained during CMSL-08, because for the first time a high space velocity of $640 \mathrm{~kg} / \mathrm{h} / \mathrm{m}^{3}$ reactor was used, coupled with the fact that it was an all dispersedcatalyst based reactor system. Thus, there was no supported catalyst in the second coal liquefaction stage for products upgrading as in the more conventional CTSL type configuration. Table 5 summarizes the poor quality of the distillate product streams when the HTU was by-passsed, with nitrogen and sulfur contents as high as $350 \mathrm{ppm}$. Upon hydrotreatment, as indicated by the shaded portions of Table 5, the SOH distillates had less than about $50 \mathrm{ppm}$ nitrogen and sulfur. 


\section{IV) Reactivity of High Density Polyethylene (HDPE):}

CMSL-09 was an extension of our efforts during CMSL-08, to define a near-optimum set of catalysts/operating conditions to improve the total conversion of mixed plastics into useful liquid products. One of the main findings during CMSL- 08 was the refractory nature of HDPE towards cracking/depolymerization, especially when fed by itself (without other plastics) with coal. Similar effects were observed during CMSL-09, with a different type of coal feed and under a different set of operating conditions and catalysts. Estimations of the conversion of HDPE to $524^{\circ} \mathrm{C}$-material are based on assuming $88 \%$ conversion of the coal residuum and $100 \%$ conversion of other plastics (PP and PS) into $524^{\circ} \mathrm{C}$ - materials (and correlating them with the actual conversions of the combined feeds to $524^{\circ} \mathrm{C}$ - materials). These are shown in Figure 11. For Condition 7 which employed mixed plastics with coal, over 90\% conversion of HDPE is estimated, while for the Condition 8, when HDPE alone was coprocessed with coal, HDPE conversion is estimated to be only $56 \%$. In Condition 9, with mixed plastics and coal, estimated HDPE conversion increased by more than $10 \%$. This behavior seems to indicate that the presence of other plastics may be instrumental in improving reactivity of HDPE under our coprocessing conditions.

\section{(V) Comparison with Exxon's Dispersed Catalyst Data:}

Condition 6 of Bench Run CMSL-09 was designed to obtain a tie-point for comparison between HTI's data and Exxon's data. Two dispersed catalysts were employed during these conditions: iron and molybdenum. At HTI, Molyvan-A was used as a source of molybdenum at $100 \mathrm{ppm}$ relative to coal, while sulfated iron oxide, prepared at HTI, was used as a source of iron at $1 \mathrm{w} \%$ relative to coal. Process performance comparisons are summarized in Table 13. Operating conditions were very similar for HTI's Condition 6 and Exxon's Conditions 3 and 4. Exxon had employed both Molyvan-A and Molyvan-L as Mo precursors, while for iron, Exxon employed Baily's -325 mesh iron oxide during Condition 3 of their run and Bayferrox fine-sized iron oxide during Condition 4. From Table 13, it can be seen that under similar conditions and catalyst loadings, HTI's Condition 6 resulted in better overall process performance. Distillate yields are about $2.5 \%$ higher and so are $524^{\circ} \mathrm{C}+$ residuum conversions. Light gas yields are slightly lower for HTI's Condition 6 , while hydrogen consumption is slightly higher, meaning the increased hydrogen consumption was utilized for the production of useful liquid products. Since all the operating conditions and Mo precursors were the same for HTI's Condition 6 and Exxon's Conditions 3 \& 4, it can be said that the better overall process performance at HTI is attributable to the use of a more active iron precursor/catalyst i.e., HTI's $\mathrm{FeOOH} / \mathrm{SO}_{4}$ catalyst.

The positive influence of the addition of $1 \mathrm{w} \% \mathrm{FeOOH} / \mathrm{SO}_{4}$ catalyst was also seen on the recycle system during CMSL-09. Towards the end of Period 9 (Condition 2), the nature of the resid material in the CAS bottoms was such that pressure filtrations became very time-consuming and finally not doable. At this point solids separation was changed to vacuum still operation. This continued well until the point in the run when an addition of iron catalyst was begun. Soon after iron catalyst was introduced with the feed at $1 \mathrm{w} \%$ level, the nature of the resid in the CAS bottoms changed to make pressure filtration operable with short turn-around times. 


\section{INTERSTAGE SAMPLES}

Interstage samples are samples of the slurry exiting the first stage coal liquefaction reactor that are withdrawn from the ebullating line on the reactor (analyses shown in Tables 10 and 11). These samples shed light on the performance of the first stage reactor in terms of coal and resid conversions. Interstage samples of product slurry from the first stage reactor were collected during all the work-up periods of CMSL-09. Analyses of the pressure filter solids from these samples indicates that about $93-94 \%$ coal conversion (based on quinoline solubility) is obtained after the first stage coal liquefaction reactor. The properties of the interstage (first stage) PFL are very consistent with the data-trends discussed earlier in this report.

\section{EXTERNAL SAMPLES}

As mentioned earlier, a number of samples of different process streams from CMSL-09 were obtained (for further detailed characterization and products assessment) for Consol, Inc. and also for members of the Consortium of Fossil Fuel Liquefaction Science. These samples, their amounts, and the operating periods when they were withdrawn are shown in Table 12.

\section{CONCLUSIONS}

CMSL-09 was a very successful bench run from both the technical and operational standpoints. Over 41 days of continuous operation was completed without any major issues/interruptions, and the main technical objectives of the run were achieved. The effects of type and amount of molybdenum based dispersed catalysts were studied, as well as two plastics/coal ratios, effects of HDPE alone, and high space velocity. Samples of different process streams were obtained for property characterization/assessment. The following conclusions can be drawn based on results from this run:

- The CTSL type reactor configuration, with an all dispersed catalyst system, results in good overall process performance, even at high feed space velocities (coal conversions over $95 \%$, resid conversions over $90 \%$, and distillate yields of over $66 \%$ ) with a sub-bituminous coal feed.

- Process performance degraded only slightly with a decrease in fresh Mo addition. Process performance was better with fresh molybdenum precursor than with recycled catalyst. HTI's sulfated iron catalyst improved overall performance when used at $1 \mathrm{w} \%$ loading relative to feed.

- Both $33 \%$ and $50 \%$ mixed plastics with coal resulted in significant improvements in distillate liquids (as high as 10-12\% maf) over 'coal-only' conditions.

- HDPE alone, with coal, was found much harder to convert to $524^{\circ} \mathrm{C}$ - material than when other plastics were present co-mingled form. 
- In-line hydrotreating was very effective for producing premium distillates with less than $50 \mathrm{ppm}$ sulfur and nitrogen.

Based upon the interesting results obtained during the last three conditions of CMSL-09 on coal/plastics coprocessing, more studies are certainly warrantied for the optimization of dispersed catalyst type and level, convertibility of HDPE to light liquids, and impact of such coprocessing on the product quality and end-use applications. It will be very interesting to follow findings from this bench run with another bench operation with the 'real life' MSW plastics. Also, the efficacy of the dispersed catalyst reactor configuration should be investigated for low quality petroleum resids/waste plastics/coal coprocessing operations. 
TABLE 1

CMSL-09 Run Plan

Condition

Periods

Feeds, W\%

Coal

HDPE

Polypropylene

Polystyrene

Temp. deg C

Pretreater

$\mathrm{K}-1$

$K-2$

HTU

$\begin{array}{lllllllll}1 & 2 & 3 & 4 & 5 & 6 & 7 & 8 & 9\end{array}$ $\begin{array}{lllllllll}1-5 & 6-9 & 10-14 & 15-19 & 20-24 & 25-29 & 30-34 & 35-38 & 39-41\end{array}$ $\begin{array}{lllllllll}100 & 100 & 100 & 100 & 100 & 100 & 67 & 67 & 50\end{array}$ $\begin{array}{lllllllll}0 & 0 & 0 & 0 & 0 & 0 & 13 & 33 & 20\end{array}$ $\begin{array}{lllllllll}0 & 0 & 0 & 0 & 0 & 0 & 11 & 0 & 16.5\end{array}$ $\begin{array}{lllllllll}0 & 0 & 0 & 0 & 0 & 0 & 9 & 0 & 13.5\end{array}$ $\begin{array}{lllllllll}300 & 300 & 300 & 300 & 300 & 300 & 300 & 300 & 300\end{array}$ $\begin{array}{lllllllll}443 & 443 & 443 & 443 & 443 & 440 & 449 & 449 & 449\end{array}$ $\begin{array}{lllllllll}449 & 449 & 449 & 449 & 449 & 449 & 460 & 460 & 460\end{array}$ $\begin{array}{lllllllll}379 & 379 & 379 & 379 & 379 & 379 & 379 & 379 & 379\end{array}$

Space Velocity

$\begin{array}{llllllllll}(\mathrm{Kg} \mathrm{feed} / \mathrm{hr} / \mathrm{m} 3) & 640 & 640 & 640 & 640 & 640 & 640 & 640 & 640 & 640\end{array}$ Slurry Cat. Conc. parts per million Mo: Molyvan-A -Fresh -Recycled $\begin{array}{lllllllll}300 & 200 & 150 & 0 & 150 & 100 & 300 & 300 & 300\end{array}$ $\begin{array}{lllllllll}0 & 0 & 150 & 300 & 150 & 100 & 300 & 0 & 0\end{array}$

$\begin{array}{lllllllllll}\mathrm{FeOOH} / \mathrm{SO} 4 & 0 & 0 & 0 & 0 & 0 & 10000 & 10000 & 10000 & 10000\end{array}$ Solid Separation** $^{\star *}$ PF VS VS VS VS VS PF PF

*Tie-Point Condition for Comparison with Exxon's latest Dispersed Catalyst Run.

${ }^{* *}$ PF - Pressure Filter; VS - Vacuum Still 


\section{TABLE 2}

'Analysis of coal and plastic ${ }^{\star}$ feedstocks for CMSL-09.

$\begin{array}{llcccc}\text { Material } & & \text { BTM Coal } & \text { HDPE } & \text { Polystyrene } & \text { Polypropylene } \\ \text { Moisture Content } & & 10.1 & & & \\ \text { Elemental, w\% dry } & & & & & \\ & \text { Carbon } & 70.12 & 85.71 & 92.31 & 85.71 \\ & \text { Hydrogen } & 5.11 & 14.29 & 7.69 & 14.29 \\ & \text { Sulfur } & 0.35 & 0 & 0 & 0 \\ & \text { Nitrogen } & 0.99 & 0 & 0 & 0 \\ & \text { Oxygen (by diff.) } & 17.24 & 0 & 0 & 0 \\ & \text { Ash, \% dry } & 6.19 & 0 & 0 & 0 \\ & & & & 2\end{array}$

*All three plastics were initially completely insoluble in either quinoline or cyclohexane. 
TABLE 3

Analysis of start-up/make-up oil for CMSL-09

HTI No.

API Gravity

$\mathrm{L}-814$

0.4

Elemental Analysis, $\overline{\mathrm{W}} \%$

Carbon

88.96

Hydrogen

8.25

Sulfur

2.22

Nitrogen

0.19

ASTM D-1160 Distillation, deg C

IBP

309

$5 \mathrm{~V} \%$

351

$10 \mathrm{~V} \%$

374

$20 \mathrm{~V} \%$

394

$30 \mathrm{~V} \%$

409

$40 \mathrm{~V} \%$

426

$50 \mathrm{~V} \%$

437

$60 \mathrm{~V} \%$

449

$70 \mathrm{~V} \%$

467

$80 \mathrm{~V} \%$

507

$84 \mathrm{~V} \%$

524

WEIGHT PERCENTS

IBP-343 Deg C

5

343-454 Deg C

53.99

454-524 Deg C

22.18

524 Deg C +

18.36

LOSS

0.47

\% Aromatic Carbon

80.03

\% Cyclic Hydrogen

44.36 
TABLE 4

\section{CMSL-09: PROCESS PERFORMANCE SUMMARY}

Unit

Run

Condition

Period Number

Hours of Run (end of Period)

W\% Plastics in Feed

Disp. Cat. ppm: Fresh Mo

Rec. Mo

Fresh Iron

Stage I Feed Space Velocity

$\mathrm{kg} \mathrm{coal} / \mathrm{hr} / \mathrm{m} 3$ reactor vol.

Temperatures, C

Pretreater

$\mathrm{K}-1$

$K-2$

Total Material Recovery \% (Gross)

$\begin{array}{cccc}/ & & & \\ 227 & 227 & 227 & 227 \\ 87 & 87 & 87 & 87 \\ 1 & 2 & 3 & 4 \\ 5 & 9^{*} & 15 & 19 \\ 120 & 216 & 360 & 456 \\ 0 & 0 & 0 & 0 \\ 300 & 200 & 150 & 0 \\ 0 & 0 & 150 & 300 \\ 0 & 0 & 0 & 0\end{array}$

$227 \quad 227$

227

227

$87 \quad 87$

$5 \quad 6$

24

576 .

0

150
150

29

696

0

100

$150 \quad 100$

10000

\section{7}

87

227

680

$666 \quad 659$

664

$678 \quad 666$

669

$303 \quad 302 \quad 305$

304

$302 \quad 302$

445

443

444

440

318

448

450

450

449

449

449

459

316

448

461

98.

102.7

98.5

99.6

$100.9 \quad 103.8$

99.2

99.1

102.1

ESTIMATED NORMALIZED YIELDS:

W\% DRY FEED

C1-C3 in Gases
C4-C7 in Gases
IBP-177 deg C
$177-260$ deg C

$\begin{array}{lll}10.96 & 10.55 \quad 12.08\end{array}$

$\begin{array}{lll}4.30 & 4.25 & 4.96\end{array}$

9.30

10.74

4.10

10.74
4.71

9.23

4.66

17.24

13.45

14.26

13.10

14.44

7.37

8.18

7.45

11.79

14.20

15.64

$17.19 \quad 14.05$

15.71

14.41

15.75

260-343 deg C

343-454 deg $C$

454-524 deg C

$524 \mathrm{deg} \mathrm{C}_{+}$

10.22

12.48

6.77

7.45

6.26

14.92

12.44

3.46

3.70

2.37
5.18

5.78

5.66

7.88

4.01

3.93

3.93

15.23

4.55

Water

COx

3.78

14.77

10.21

4.77

7.35

4.34

15.58

12.76

14.96

13.22

3.10

4.81

4.38

5.37
0.97

0.97

0.88

0.88

0.86

H2S

0.03

$-0.03$

0.16

0.08

$-0.17$

$-0.15$

4.51

21.43

4.65

8.52

14.87

16.31

10.32

12.18

11.41

3.92

2.16

18.31

4.6

5.41

10.26

1.67

0.56

16.1

4.31

10.5

2.82

0.51

$-0.05$

$-0.1$

7.31

7.20

$6.17 \quad 6.69$

5.87

6.26

5.75

4.56

4.14

5.44

23.64

11.54

13.88

13.26

4.31

8.61

2.92

7.15

2.07

0.38

$-0.04$

Hydrogen Consumption

PROCES̄S PERFORMANCE

Feed Conversion, W\% maf Feed

$524 \mathrm{C}+$ Conversion, W\% maf Feed

95.8

95.8

$91.9 \quad 90.3$

95.2

95.

95.

66.6

63.3

89.0

84.4

86.6

96.1

95.3

95.5

97.0

C4-524 C Distillates, W\% maf Feed

62.2

60.0

62.4

87.6

92.1

78.7

88.1

"Data from Period 8 has been used to evaluate the Work-up Period 9. 
TABLE 5

\section{Hydrotreater Performance during CMSL-09}

[All numbers in parts per million]

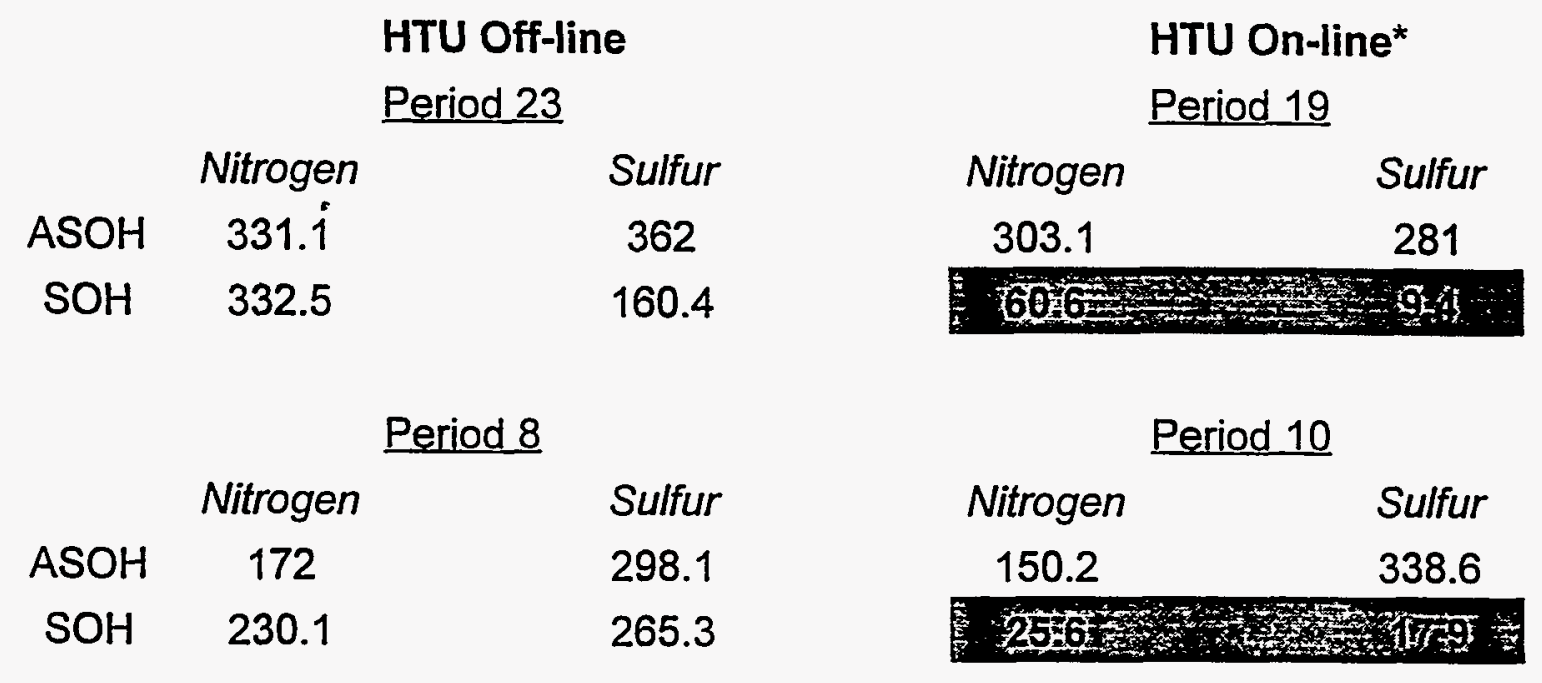

*The shaded numbers are for Hydrotreated Distillate Products. 
TABLE 6

CMSL-09: SEPARATOR OVERHEAD (SOH) INSPECTION

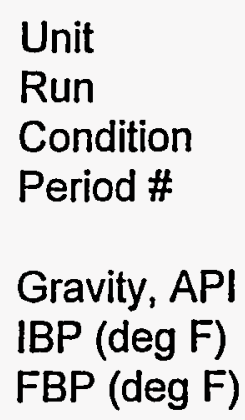

ASTM D-86 Distillation, Compostion

$$
\text { W\% IBP-350 deg } F
$$
W\% 350-500 W\% 500-650 W\% 650+

W\% Loss

Elemental Analysis

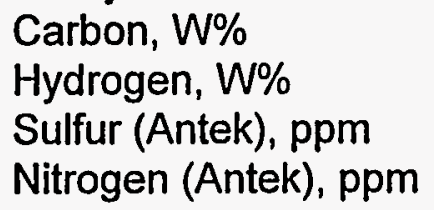

H/C Ratio

227
87
1
5

227
87
2
9

227

$227 \quad 227$

\section{5}

138

34.9
136

87
3

87

227
87

$4 \quad 5$

15

4
19

24

34.5
143

34.2

32.1

142

714

131

720

227
87
6
29

$\begin{array}{ccc}227 & 227 & 227 \\ 87 & 87 & 87 \\ 7 & 8 & 9 \\ 34 & 38 & 41\end{array}$

35.83

22.98

32.74

7.98

0.47

$\begin{array}{cc}35.1 & 33.1 \\ 29.9 & 29.8 \\ 27.5 & 29.9 \\ 7.1 & 7.2 \\ 0.4 & 0\end{array}$

33.5
28.6
29.9
8
0

31.7
29.4
30.4
8
0.5

21.1
38.2
32
8.4
0.3

\section{2}

136

707

39.4

$$
135
$$

135
689

39.9

161

43.8

136

715

$\begin{array}{ccccccccc}86.4 & 87.09 & 87.25 & 87.15 & 86.84 & 84.44 & 86.86 & 86.06 & 86.14 \\ 13.01 & 12.7 & 12.54 & 12.46 & 12.26 & 10.68 & 12.74 & 13.39 & 13.06 \\ 7 & 17.9 & 14.8 & 9.4 & 89.2 & 195.9 & 8.6 & 17 & 34.2 \\ <1 & 25.6 & 36 & 60.6 & 152.9 & 206.6 & 47.2 & 23.8 & 10.5 \\ 1.81 & 1.75 & 1.72 & 1.72 & 1.69 & 1.52 & 1.76 & 1.87 & 1.82\end{array}$


TABLE 7

CMSL-09: ATMOSPHERIC OVERHEAD (ASOH) INSPECTION

Unit
Run
Condition
Period \#
Gravity, API
IBP (deg C)
FBP (deg C)

ASTM D-86 Distillation, Compostion W\% IBP-177 deg C W\% 177-260 W\% 260-343 W\% 343+ W\% Loss

Elemental Analysis

Carbon, W\%

Hydrogen, W\%

Sulfur (Antek), ppm

Nitrogen (Antek), ppm

H/C Ratio

$\begin{array}{cccccccc}227 & 227 & 227 & 227 & 227 & 227 & 227 & 227 \\ 87 & 87 & 87 & 87 & 87 & 87 & 87 & 87 \\ 1 & 2 & 3 & 4 & 5 & 6 & 7 & 8 \\ 5 & 9 & 15 & 19 & 24 & 29 & 34 & 38 \\ & & & & & & & \\ 12.9 & 10.6 & 14.2 & 14 & 13.6 & 3.3 & 27 & 24.4 \\ 77.8 & 167.8 & 88.9 & 78.3 & 77.2 & 75.6 & 71.1 & 80.6 \\ 393.9 & 395.6 & 392.2 & 389.4 & 391.1 & 390.0 & 392.2 & 398.3\end{array}$

$\begin{array}{cccccccc}7.86 & 0 & 6.2 & 5.3 & 5.6 & 4.1 & 30.3 & 16.6 \\ 22.35 & 14.1 & 25.8 & 23.3 & 22.4 & 16.1 & 25.1 & 32.5 \\ 35 & 51.1 & 43.7 & 44.9 & 44.6 & 29.05 & 29.7 & 25.4 \\ 34.69 & 34.4 & 24.3 & 26 & 26.9 & 50.47 & 14.6 & 25.2 \\ 0.1 & 0.4 & 0 & 0.5 & 0.5 & 0.28 & 0.3 & 0.3\end{array}$

$\begin{array}{cccccccc}85.69 & 86.18 & 85.92 & 85.88 & 86.05 & 79.92 & 85.82 & 84.54 \\ 9.63 & 9.19 & 9.6 & 9.53 & 9.53 & 7.77 & 10.51 & 10.79 \\ 375.7 & 338.6 & 298.1 & 281 & 362 & 290 & 205 & 352 \\ 263.6 & 150.2 & 172 & 303.1 & 331.1 & 372 & 692.6 & 741 \\ & & & & & & & \\ 1.35 & 1.28 & 1.34 & 1.33 & 1.33 & 1.17 & 1.47 & 1.53\end{array}$


TABLE 8

CMSL-09: PROPERTIES OF THE PRESSURE FILTER LIQUID (2nd Stage)*

\begin{tabular}{|c|c|c|c|c|c|c|c|c|c|}
\hline Unit & $' 227$ & 227 & 227 & 227 & 227 & 227 & 227 & 227 & 227 \\
\hline Run & 87 & 87 & 87 & 87 & 87 & 87 & 87 & 87 & 87 \\
\hline Condition & 1 & 2 & 3 & 4 & 5 & 6 & 7 & 8 & 9 \\
\hline Period \# & 5 & 9 & 15 & 19 & 24 & 29 & 34 & 38 & 41 \\
\hline Gravity, API & -2.5 & 3.7 & 3.9 & 2.3 & 3.8 & 5.8 & 11.1 & 9.9 & 11.5 \\
\hline IBP (deg F) & 407 & 420 & 427 & 497 & 425 & 408 & 379 & 463 & 455 \\
\hline \multicolumn{10}{|c|}{ ASTM D-1160 Distillation, Compostion } \\
\hline W\% IBP-650 deg F & 17.14 & 30.09 & 34.74 & 20.38 & 28.49 & 33.95 & 32.36 & 10.99 & 11.92 \\
\hline W\% 650-850 & 43.76 & 67.24 & 62.11 & 77.64 & 68.64 & 62.46 & 66.03 & 37.66 & 37.88 \\
\hline W\% 850-975 & 12.03 & 0 & 2.58 & 1.89 & 2.49 & 3.1 & 1.21 & 11.29 & 16.67 \\
\hline W\% 975+ & 26.44 & 2.39 & 0 & 0 & 0 & 0 & 0 & 39.66 & 33.33 \\
\hline W\% Loss & 0.63 & 0.28 & 0.57 & 0.09 & 0.38 & 0.49 & 0.4 & 0.4 & 0.2 \\
\hline \multicolumn{10}{|l|}{ Elemental Analysis } \\
\hline Carbon, W\% & 88.37 & 87.32 & 87.8 & 88.63 & 87.91 & 87.65 & 87.52 & 87.21 & 87.04 \\
\hline Hydrogen, W\% & 7.34 & 8.13 & 8.35 & 8.27 & 8.47 & 8.65 & 9.25 & 11.67 & 10.98 \\
\hline Sulfur, W\% & 0.842 & 0.551 & 0.22 & 0.365 & 0.263 & 0.28 & 0.394 & 0.332 & 0.194 \\
\hline Nitrogen, W\% & 0.79 & 0.71 & 0.82 & 0.81 & 0.87 & 0.78 & 0.7 & 0.43 & 0.48 \\
\hline H/C Ratio & 1.00 & 1.12 & 1.14 & 1.12 & 1.16 & 1.18 & 1.27 & 1.61 & 1.51 \\
\hline CCR, W\% PFL & 59.55 & & & & & & & 21.2 & 15.4 \\
\hline Cyclohexane Insolubles, W\% & 76.75 & & & & & & & 54.77 & 42.1 \\
\hline Toluene Insolubles, W\% & 16.3 & & & & & & & 35.28 & 46.01 \\
\hline
\end{tabular}

*For Periods 9-34, since vacuum still was used in plasce of pressure filtration for solids separation, the analysis of VSOH is listed. 
TABLE 9

\section{CMSL-09: INSPECTION OF THE PRESSURE FILTER SOLID (2nd Stage)*}

Unit

Run

Condition

Period \#

Elemental Analysis

Carbon, W\%

Hydrogen, W\%

Sulfur, $\mathrm{W} \%$

Nitrogen, W\%

H/C Ratio

Composition, W\%

Ash (Quinoline Filtration)

ASTM Ash

Sulfur in Ash

QI Including Ash

Metals Analysis, w\%

Molybdenum

Iron

3.99

0.508
3.486

0.365
3.32

0.224
3.35

3.29

7.47

28.33

30.11

2.85

47.1

30.05

30.87

3.06

51.55

32.58

33.44

5.65

49.75

26.17

26.97

4.34

54.78

37.88

7.89

65.24

0.56

6.13

0.654

8.1

1.55

13.39

* Periods 9-34, since vacuum still was used for solids separation, the analyses of VSB are listed. 
TABLE 10

\section{CMSL-09: PROPERTIES OF THE PRESSURE FILTER LIQUID (1st Stage)}

Unit

Run

Condition

Period \#

Gravity, API

IBP (deg C)

$\begin{array}{ccccccc}227 & 227 & 227 & 227 & 227 & 227 & 227 \\ 87 & 87 & 87 & 87 & 87 & 87 & 87 \\ 1 & 2 & 3 & 4 & 5 & 6 & 7 \\ 5 & 9 & 15 & 19 & 24 & 29 & 34\end{array}$

ASTM D-1160 Distillation, Compostion W\% IBP-343 deg C

W\% 343-454

W\% 454-524

W\% 524+

W\% Loss

$\begin{array}{ccccccc}-6.2 & -3.1 & -3 & -4.6 & -3.7 & -0.6 & 4 \\ 223.333 & 217.222 & 228.333 & 236.667 & 222.778 & 225 & 252.222\end{array}$

$\begin{array}{ccccccc}10.98 & 15.61 & 14.17 & 12.47 & 16.35 & 14.61 & 11.3 \\ 36.94 & 42.47 & 37.33 & 39.55 & 37.4 & 42.74 & 39.85 \\ 14.35 & 13.98 & 13.99 & 12.83 & 13.28 & 15.08 & 11.49 \\ 37.02 & 27.22 & 33.79 & 34.71 & 32.34 & 26.83 & 36.97 \\ 0.71 & 0.72 & 0.72 & 0.44 & 0.63 & 0.74 & 0.39\end{array}$

Elemental Analysis

\section{Carbon, W\%}

Hydrogen, W\%

Sulfur, W\%

Nitrogen, W\%

$\begin{array}{ccccccc}88.3 & 87.54 & 87.57 & 87.87 & 87.91 & 87.64 & 88.38 \\ 7.05 & 7.53 & 7.62 & 7.48 & 7.42 & 7.79 & 9.22 \\ 0.82 & 0.543 & 0.412 & 0.274 & 0.299 & 0.496 & 0.201 \\ 0.79 & 0.96 & 0.99 & 1.06 & 1.02 & 0.89 & 0.75 \\ & & & & & & \\ 0.96 & 1.03 & 1.04 & 1.02 & 1.01 & 1.07 & 1.25 \\ & & & & & & \\ 59.85 & 53.46 & 49.21 & 51.76 & 54.88 & 53.15 & 33.59 \\ & 66.66 & 56.27 & 63.94 & 64.24 & 55.27 & 59.48 \\ & 21.55 & 17.27 & 16.65 & 18.62 & 16.07 & 24.75\end{array}$

H/C Ratio

CCR, W\% PFL

Cyclohexane Insolubles, W\%

21.55

17.27

16.65

24.75 
TABLE 11

CMSL-09: INSPECTION OF THE PRESSURE FILTER SOLID (1st Stage)

Unit

Run

Condition

Period \#

$\begin{array}{ccccccc}227 & 227 & 227 & 227 & 227 & 227 & 227 \\ 87 & 87 & 87 & -87 & 87 & 87 & 87 \\ 1 & 2 & 3 & 4 & 5 & 6 & 7 \\ 5 & 9 & 15 & 19 & 24 & 29 & 34\end{array}$

Elemental Analysis

Carbon, W\%

Hydrogen, W\%

Sulfur, W\%

Nitrogen, W\%

H/C Ratio

$\begin{array}{ccccccc}60.82 & 55.46 & 56.43 & 56.01 & 55.78 & 55.6 & 53.72 \\ 3.8 & 3.43 & 3.64 & 3.5 & 3.59 & 3.7 & 3.91 \\ 1.57 & 1.29 & 1.53 & 1.38 & 1.2 & 2.78 & 2.69 \\ 0.75 & 0.7 & 0.66 & 0.67 & 0.68 & 0.66 & 0.6 \\ & & & & & & \\ 0.75 & 0.74 & 0.77 & 0.75 & 0.77 & 0.80 & 0.87\end{array}$

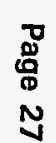

Composition, W\%

Ash (Quinoline Filtration)
ASTM Ash
Sulfur in Ash
Ql including Ash

26.11

26.82

30.99

3.61

30.92

3.41

31.03

32.14

35.71

37.26

37.07

51.66

59.38

3.76

33

32.5

3.16

6.33

37.75

53.99

54.49

54.9

59.62

65.71 
TABLE 12

\section{Hydrocarbon Technologies, Inc. SHIPPING REQUEST FORM}

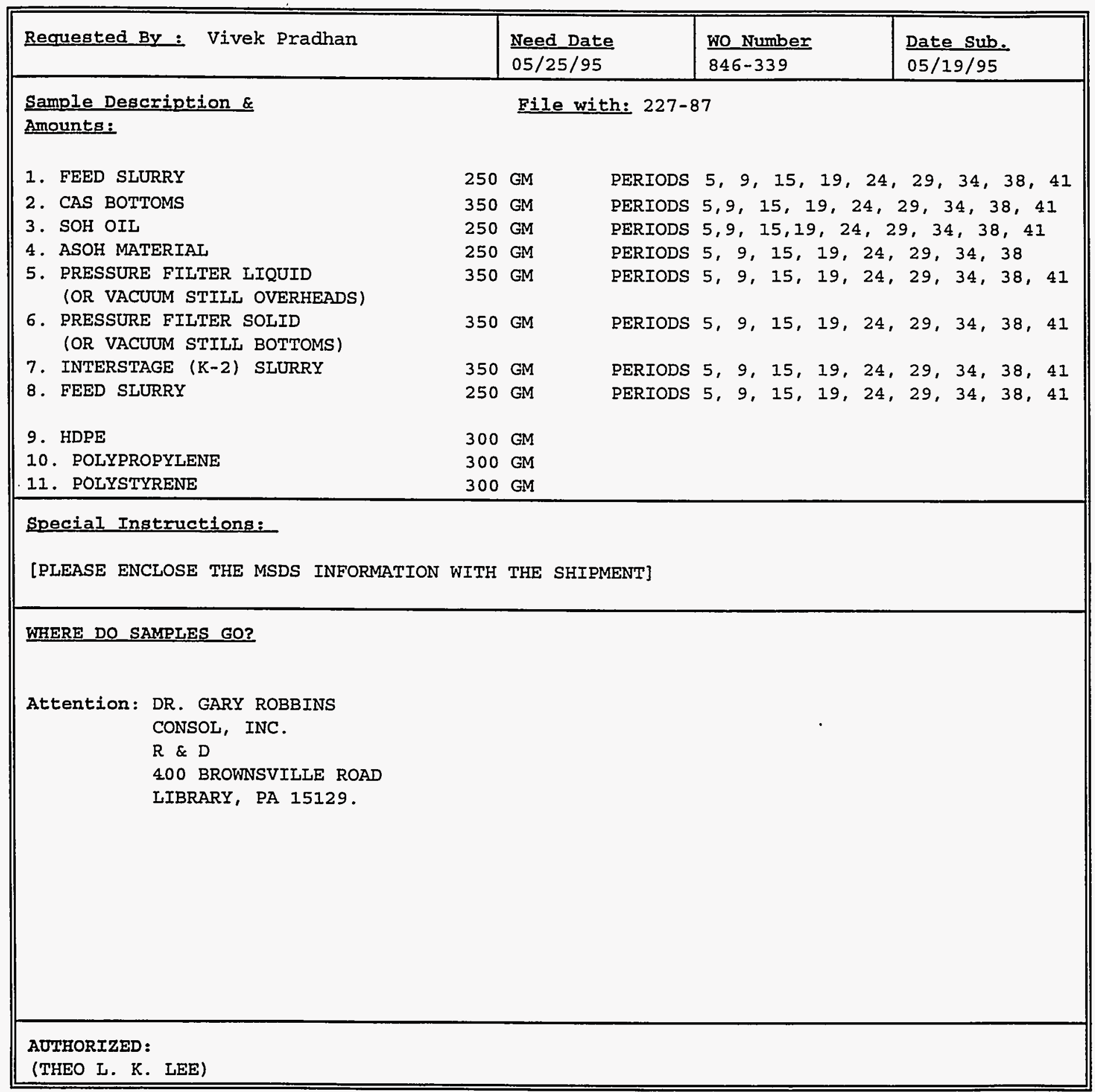


TABLE 13

\section{Comparison Between CMSL-09 Condition 6 and Exxon's Data}

Run

Condition

Residence Time, min

Temperatures, $\operatorname{deg} \mathrm{C}$

Pretreater
Reactor K-1
Reactor K-2
Hydrotreater

Catalysts
Molybdenum
ppm
Iron
w\%

Yields (MAF)

C1-C3
C4-538 C
C4-177 C
$177-343$ C
$343-538$ C

Coal Conversion, \%maf $538 \mathrm{C}+$ Resid Conv., \% maf

Hydrogen Consumption, \%maf
$\mathrm{HTl} l^{*}$

6

40

300

440

449

379

Molyvan-A

100 ppm

$\mathrm{FeOOH} / \mathrm{SO} 4$

$1 \%$
Exxon

3

41

41

Exxon

300

439

450

N/A

N/A N/A

$\begin{array}{cc}\text { Molyvan- } A & \text { Molyvan-L } \\ 100 \mathrm{ppm} & 100 \mathrm{ppm} \\ \text { Baily } & \text { Bayferrox } \\ 1 \% & 1 \%\end{array}$

* HTI's data represents the C4-524 C distillate fraction and $524 \mathrm{C}+$ Resid Conversi instead of C4-538 C yield and $538 \mathrm{C}+$ Resid conversions in Exxon's data. 


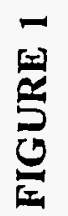

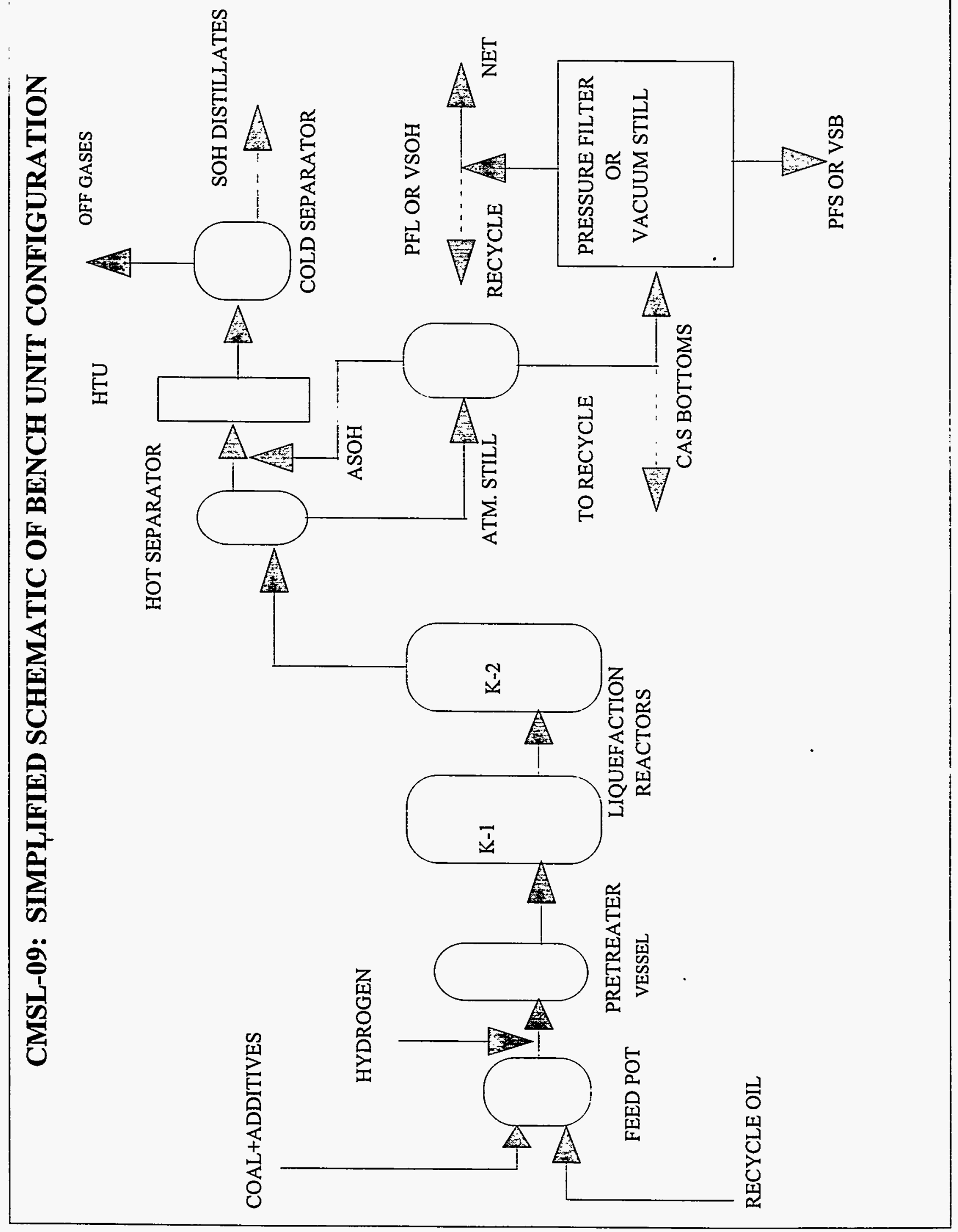

Page $\mathbf{3 0}$ 


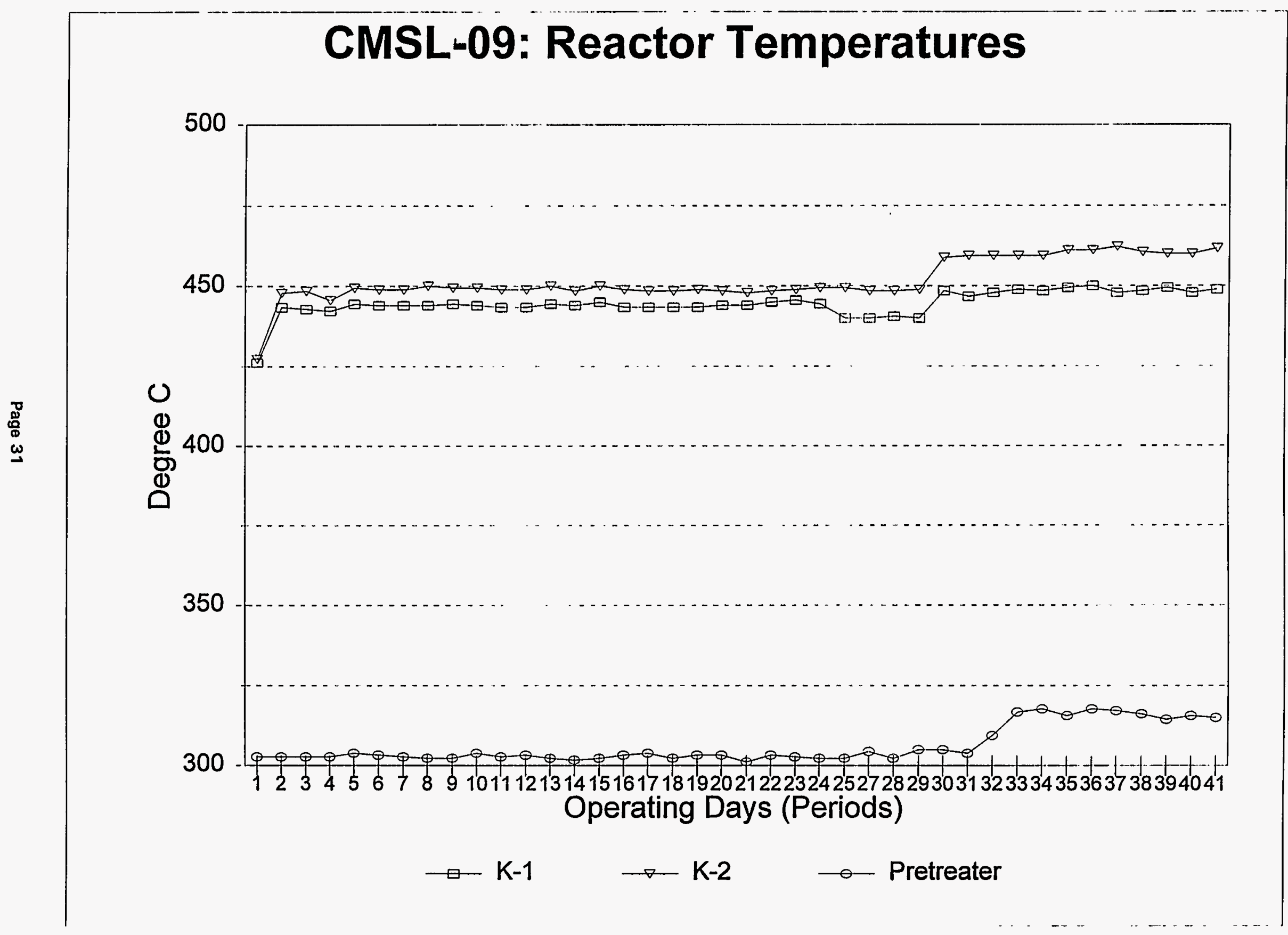


FIGURE 3

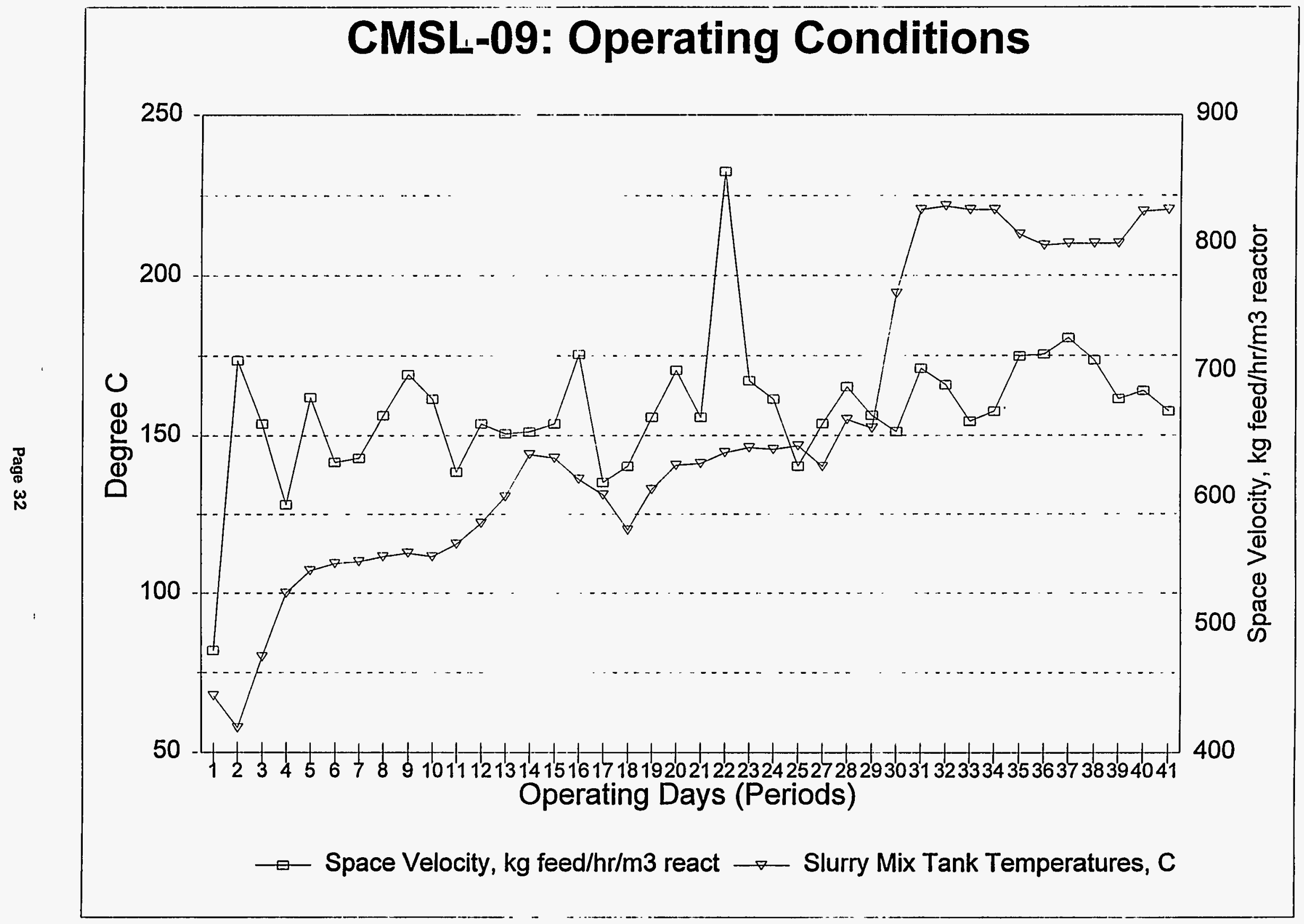




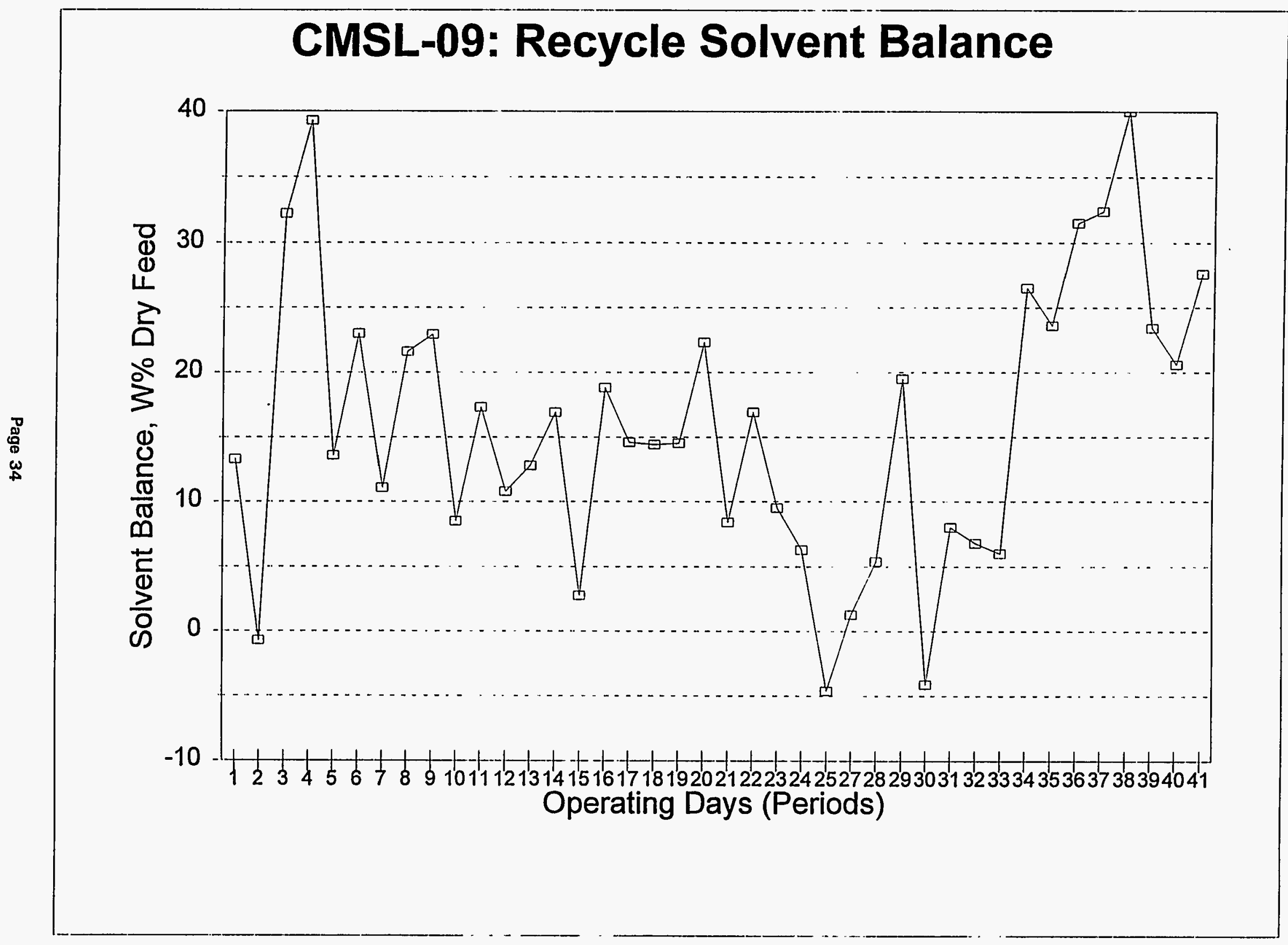


告

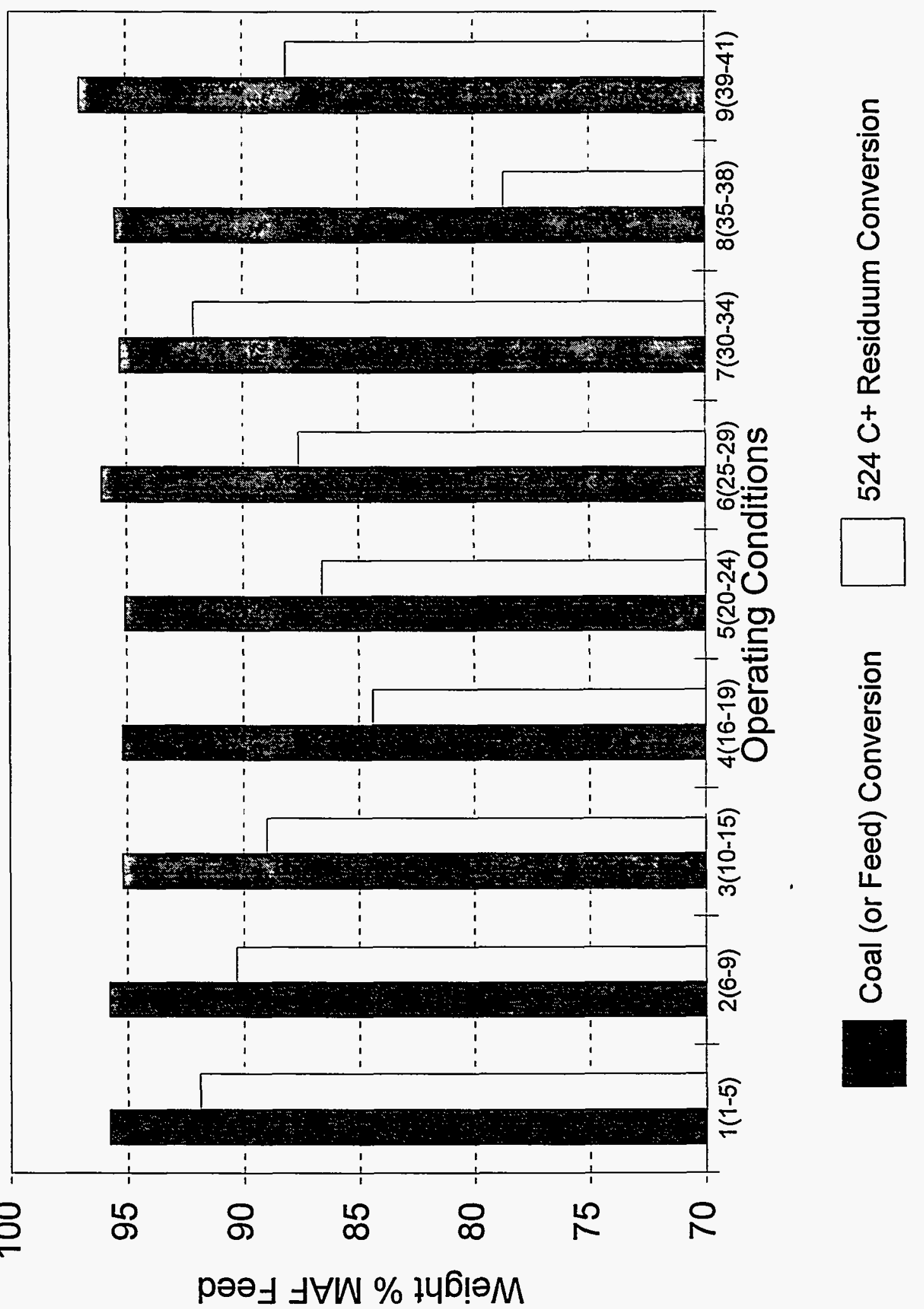




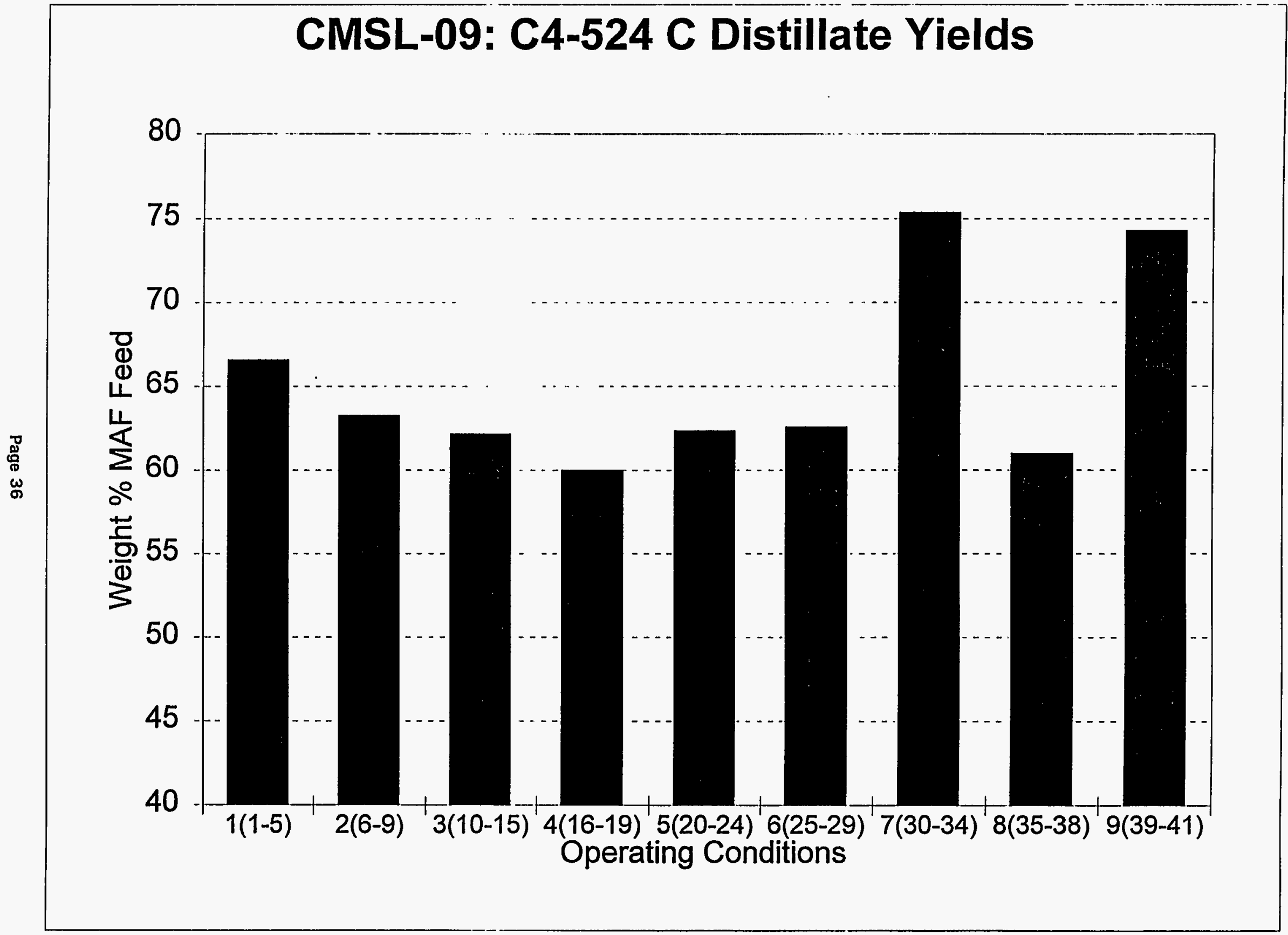


FIGURE 8

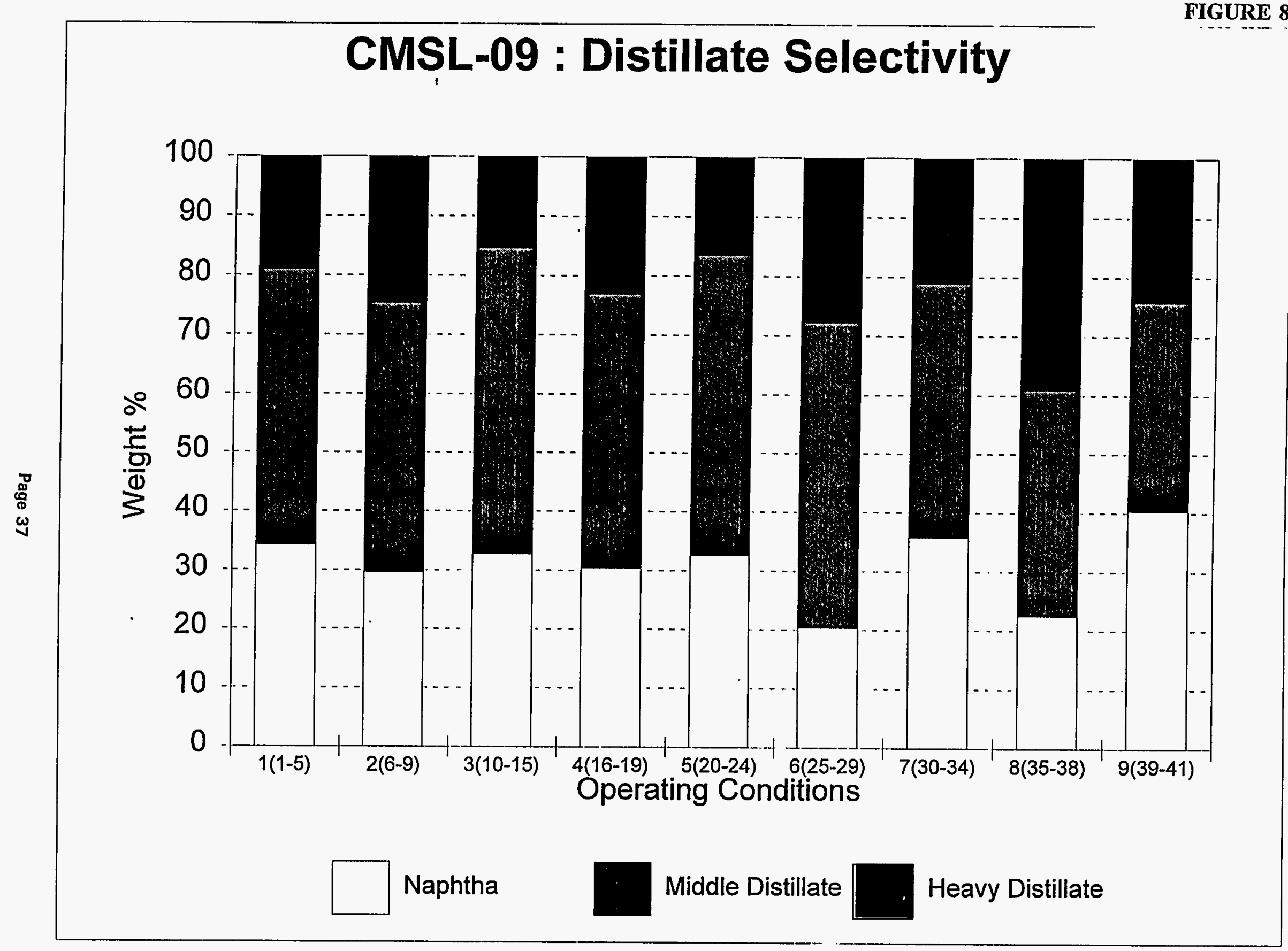


FIGURE 9

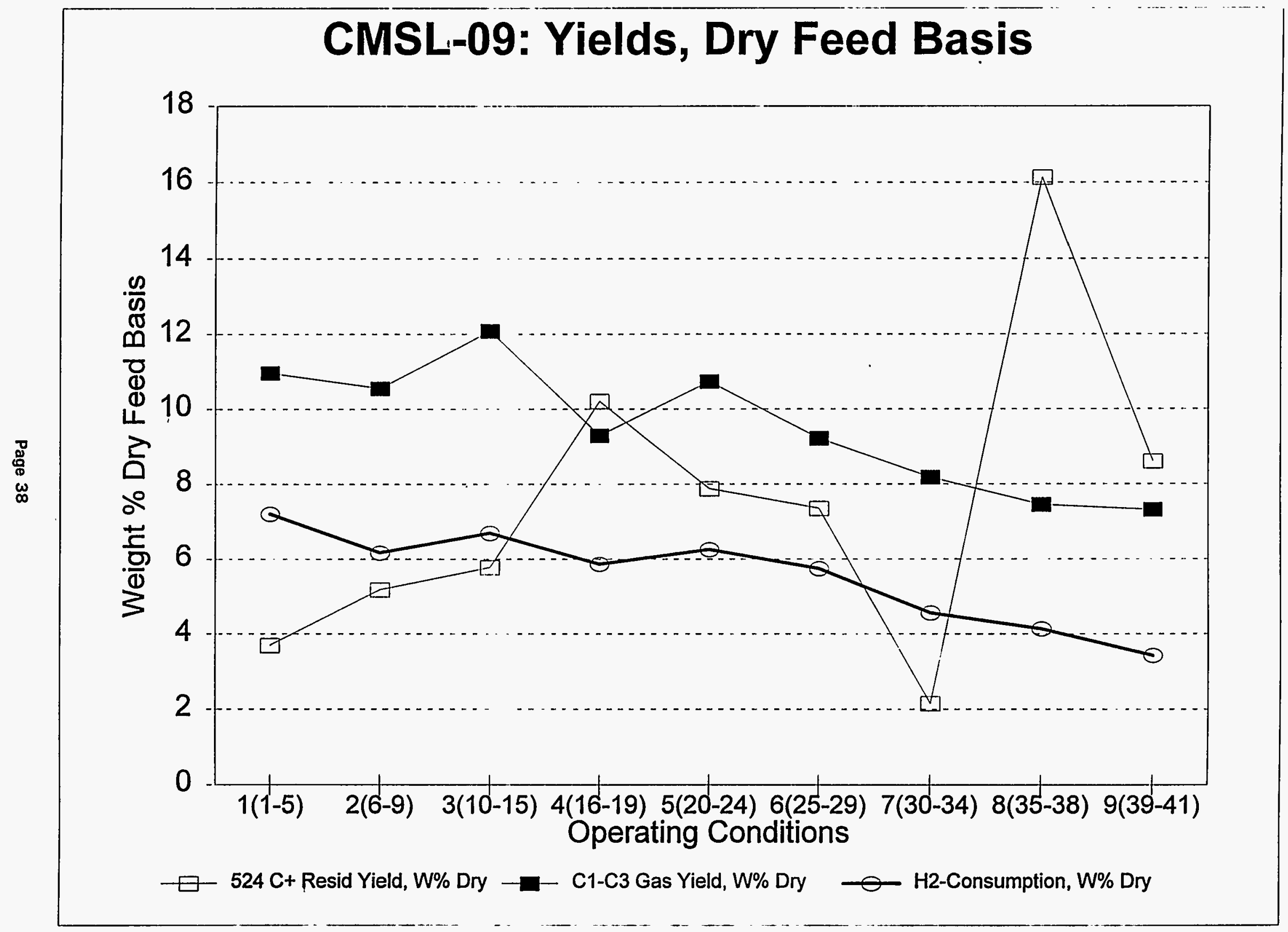


옴

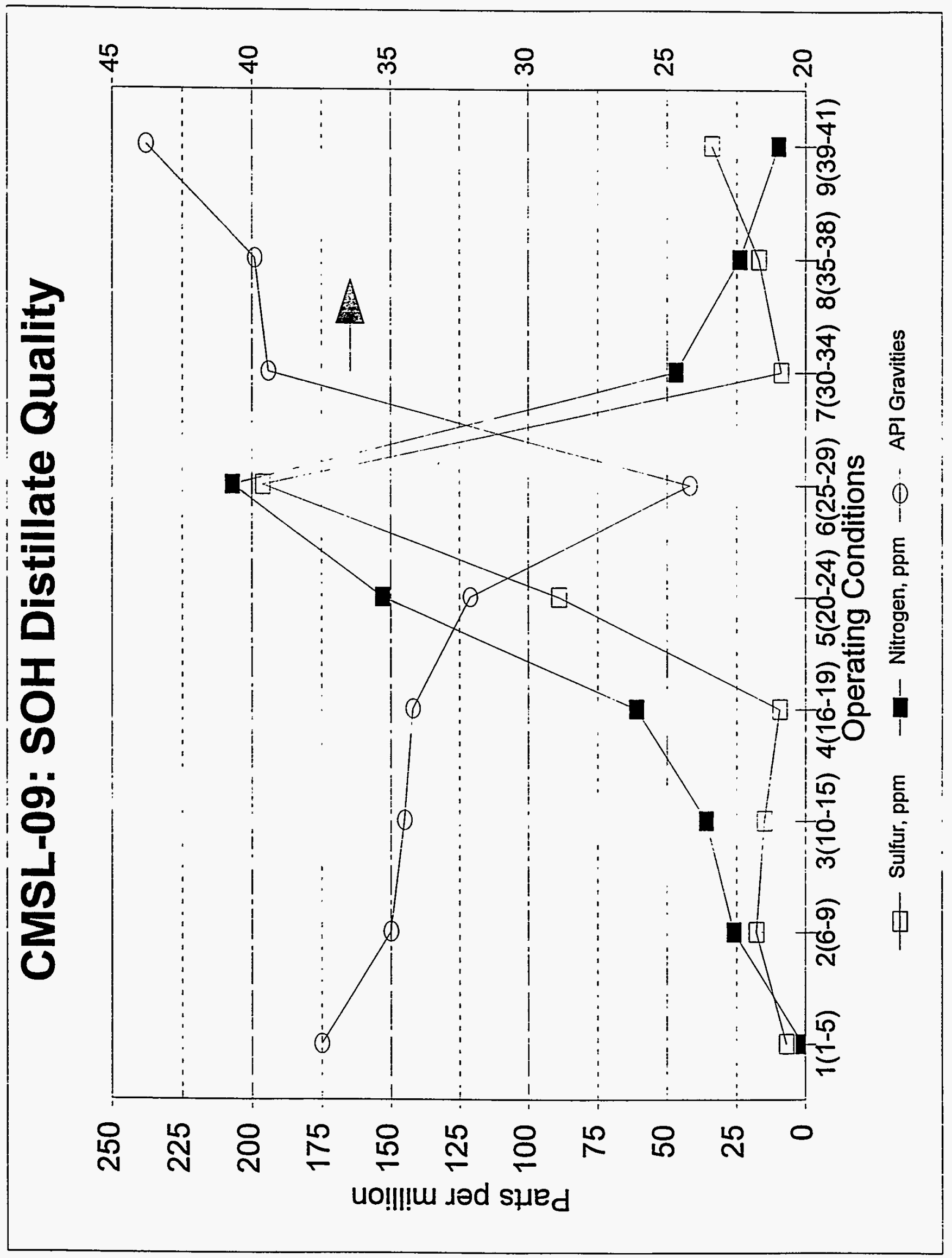




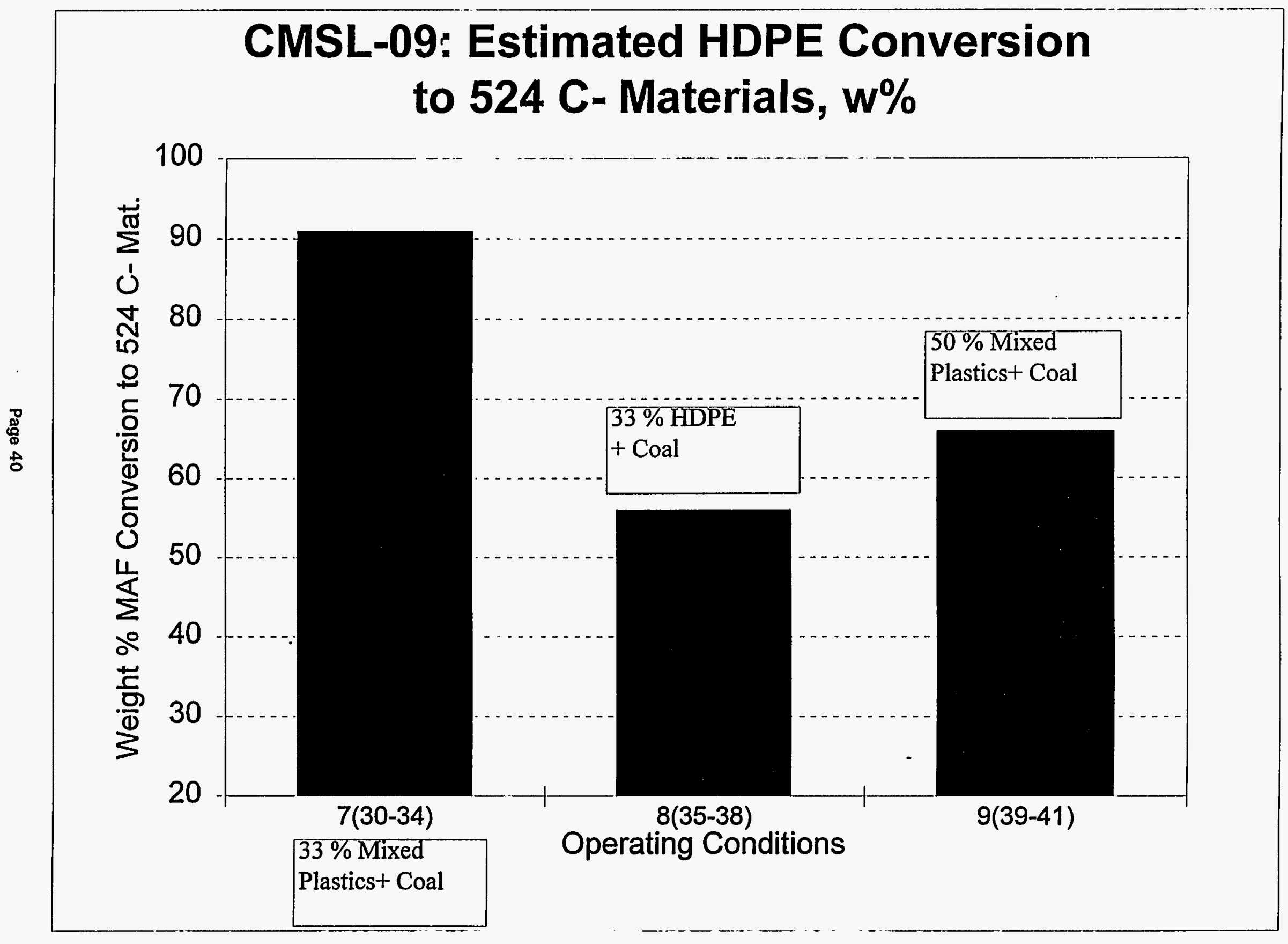




\section{RUN CMSL-10 (227-88)}

\section{EVALUATION OF A COMBINED IRON-MOLYBDENUM DISPERSED SLURRY CATALYST SYSTEM FOR LIQUEFACTION OF BLACK THUNDER MINE COAL}

\section{SUMMARY}

Bench Run CMSL-10 (HTI Run 227-88) was designed as a follow-up study after Bench Run CMSL-09. During CMSL-09, for the first time at HTI, an all dispersed (slurry) catalyst reactor system was used for coal liquefaction and coal/waste plastics coprocessing. Interestingly, the performance of the multi-stage coal liquefaction unit, under suitable reaction severity with an inline hydrotreater, was found to surpass the earlier process performance using ebullated bed reactors with supported catalysts. This result was very significant, as dispersed slurry catalysts based on iron and molybdenum, are not only more economical to use than supported catalysts, but they also have tremendous potential to lower overall operational costs for coal liquefaction by elimination of the expensive ebullated bed reactors. The effects of iron-based HTI properietery catalyst and molybdenum, added as Molyvan-A, were not fully understood during CMSL-09. One of the main objectives of CMSL-10 was to further our understanding of the effects of iron and molybdenum employed alone and added together on process performance. The mode of addition of HTI's iron catalyst and process severity (reactor temperatures and space velocity) were among the variables studied during CMSL-10.

The entire run was spread over 16 days of continuous operations. Because of a shut-down at the beginning of the run, brought about by a high pressure drop in the low-temperature $\left(300^{\circ} \mathrm{C}\right)$ pretreater reactor, the actual run spanned Periods 3 to 18 . Overall, four conditions were studied during this run: Condition 1 studied the effects of adding $0.5 \mathrm{w} \%$ of HTI's iron catalyst in dry, powdered form at a coal space velocity of 640 and reactor temperatures of 441 and $449^{\circ} \mathrm{C}$, respectively. Condition 2 looked at the effect of adding $100 \mathrm{ppm}$ molybdenum as Molyvan-A, together with iron, on process performance. Unfortunately, due to resid build up in the recycle solvent, coal space velocity had to be reduced to below $480 \mathrm{~kg} / \mathrm{h} / \mathrm{m}^{3}$ reactor. In conditions 3 and 4 , a wet iron catalyst cake was used as the source of iron at $0.5 \mathrm{w} \%$ relative to feed coal and 100 ppm molybdenum from Molyvan-A. In Condition 3, space velocity was back to $640, \mathrm{~kg} / \mathrm{h} / \mathrm{m} 3$ while in Condition 4, space velocity was increased to about $800 \mathrm{~kg} / \mathrm{hr} / \mathrm{m}^{3}$ reactor. To counter the increased space velocity, reactor temperatures were raised to 449 and $460^{\circ} \mathrm{C}$ for reactors $\mathrm{K}-1$ and $\mathrm{K}-, 2$ respectively.

In general, light hydrocarbon gas yields during this run were on the high side (11-16\% maf coal); maf coal conversion varied between about 92 to $96 \mathrm{w} \%$. First stage (interstage) maf coal conversion levels were between 91-93.5 w\%. Resid conversion varied between 83-91 w\% maf, while the yields of light distillates varied between about 57 to $64 \mathrm{w} \%$ maf coal. It was evident from Condition 1 that, under the prevailing operating conditions, iron alone at $0.5 \mathrm{w} \%$ was not a great catalyst, giving an ordinary performance, i.e., $57 \%$ distillate yield, $83 \%$ resid conversion, and $92 \%$ total coal conversion (all maf bases). After reducing the space velocity and adding 
$100 \mathrm{ppm}$ of molybdenum, (Condition 2, the process performance improved considerably to, about $64 \%$ distillates, $90 \%+$ resid conversion, and $94+\%$ total coal conversion. A further increase in space velocity back to 640 (similar to Condition 1 ) reduced yields and conversion, although these were distinctly higher than those obtained during Condition 1 . This proves the utility of molybdenum as a co-catalyst with iron; also it can be said that changing the mode of addition of HTI's iron catalyst did not make any difference in its catalytic function/activity. This point is important because in the new mode of addition of HTI's iron catalyst, two major processing steps in the catalyst synthesis could be eliminated completely, bringing about substantial reduction in the cost of dispersed catalyst. The last run Condition, Condition 4, was made with increased space velocity and increased reactor temperatures, giving marginally better overall performance than Condition 3. Thus, the operability of the unit at high coal throughputs was successfully demonstrated. .

\section{BACKGROUND, OBJECTIVE, AND SCOPE OF WORK}

Bench Run CMSL-10 was carried out, as a follow-up to CMSL-09, using a dispersed catalystonly, two-stage, backmixed reactor system. The two conversion reactors were preceded by a back-mixed pretreatment reactor at lower temperature and half the capacity (volume) of each of the conversion reactors. The pretreatment reactor was intended for sulfidation/activation of the dispersed catalyst additive. Bench Run CMSL-10 was eighteen days long, comprising four operating conditions (3-5 days each). The objectives of this bench operation were:

- To determine process performance for a subbituminous coal liquefaction using a three-stage (including pre-treater) dispersed catalyst-only back-mixed reactor system.

- To investigate the effects of a combined catalytic system of molybdenum and iron on process performance.

- To determine the effects of process severity (temperatures and space velocities) on performance.

- To determine the effects of the mode of addition of HTI's iron catalyst process performance.

An in-line hydrotreater was used during this run. Both hot separator (O-1) overheads and atmosheric still overheads (ASOH) were sent through the hydrotreater.

The run plan (Table 14) included four run conditions that were selected to meet the technical objectives specified above. By not using a supported extrudate catalyst in any of the coal liquefaction reactors, it became possible to compare the process performance of different run conditions on a one-to-one basis without being affected by 'catalyst batch-deactivation' phenomenon typical of bench CTSL operations. Condition 1 studied the effects of adding $0.5 \mathrm{w} \%$ of HTI's iron catalyst in dry, powdered form on process performance at a coal space velocity of $640 \mathrm{~kg} / \mathrm{h} / \mathrm{m} 3$ and reactor temperatures of 441 and $449^{\circ} \mathrm{C}$, respectively. Condition 2 looked at the 
effect of adding $100 \mathrm{ppm}$ molybdenum as Molyvan-A, together with iron, on process performance. Unfortunately, due to resid build up in the recycle solvent, the coal space velocity had to be reduced to below $480 \mathrm{~kg} / \mathrm{h} / \mathrm{m}^{3}$ reactor. Conditions 3 and 4 used a wet iron catalyst cake as the source of iron at $0.5 \mathrm{w} \%$ relative to feed coal plus $100 \mathrm{ppm}$ molybdenum from MolyvanA. In Condition 3 the space velocity was back to $640 \mathrm{~kg} / \mathrm{h} / \mathrm{m} 3$, while in Condition 4 space velocity was increased to about $800 \mathrm{~kg} / \mathrm{h} / \mathrm{m}^{3}$ reactor. To counter the increased space velocity, reactor temperatures were raised to 449 and $460^{\circ} \mathrm{C}$ for reactors $\mathrm{K}-1$ and $\mathrm{K}-2$, respectively.

\section{SYSTEM CONFIGURATION:}

CMSL-10 involved two equal volume backmixed reactors, one half volume $(1000 \mathrm{cc})$ pretreatment vessel (also backmixed), and a fixed-bed hydrotreater. High pressure slurry samples were obtained both after the pretreatment vessel and after the first conversion reactor. A simplified schematic of this configuration is shown in Figure 12.

The reactors from the existing units 227 and 238 were used in this run with the necessary repiping and equipment modifications. A hot-slurry mix tank system was used throughout the run for slurry preparation. No supported catalyst was used in any of the conversion reactors, except in the hydrotreater (HTU). Hydrogen sulfide $\left(\mathrm{H}_{2} \mathrm{~S}\right)$, as the source of sulfur for activation of the dispersed iron and molybdenum additives, was continually added to the pretreater at $3 \mathrm{w} \%$ of dry coal.

\section{COAL FEED, STARTUP AND MAKEUP OL}

Subbituminous Black Thunder Mine Coal (HRI-6213), the same coal that was used in PDU 260-005 (POC-02 Run), was used for CMSL-10 (227-88). Tank 4 material (L-814) , a combination of hydrotreated petroleum-derived oil with small amounts of coal-derived liquid obtained during POC- 02 was used as startup and makeup oil. The same combination of feed coal and make-up oil was employed during CMSL-09.

\section{CATALYST}

Hydrotreater:

Pretreater (carried over to $\mathrm{K}-1$ and $\mathrm{K}-2$ ):
Criterion C-411 Trilobe (HRI-6135)

Molyvan-A, HTI's Fe Catalyst, and 3

$\% \mathrm{H}_{2} \mathrm{~S}$ relative to dry coal. 


\section{OPERATIONAL DETAILS}

Bench run CMSL-10 consisted of four run conditions. For the entire run, an average material recovery balance of $101.1 \mathrm{~W} \%$ was achieved. A summary of the material balance on a daily basis is plotted in Figure 13. Since the major objective of CMSL-10 was to study the effects of combined $\mathrm{Mo} / \mathrm{Fe}$ catalysts and space velocity on the conversion of coal, this run was originally planned to operate at constant temperature and pressure. Reactor space velocities, and temperatures during CMSL-10 are summarized in Figure 14. Space velocity was adjusted between 415 and $731 \mathrm{~kg} / \mathrm{h} / \mathrm{m} 3$ to examine its impact on process performance. The viscosity of the feed slurry was measured throughout the run and no significant change that might affect pumpability was observed. Unit back pressures were controlled and recorded on an hourly basis. Process operation was similar to run CMSL-9 except that no CAS bottoms was recycled and no ASOH sample was taken during run CMSL-10. Operating conditions and process performance during CMSL-10 are summarized in Table 15. Dispersed catalyst concentrations for different run conditions are shown in Figure 15.

\section{PROCESS PERFORMANCE}

\section{TOTAL COAL CONVERSION}

Total coal conversion is calculated on the basis of the solubility of pressure filter solids in quinoline. Coal conversions for different conditions are shown in Figure 16. Throughout the course of Run 227-88, coal conversion varied between $92 \mathrm{~W} \%$ and $96 \mathrm{~W} \%$, maf. Only $\mathrm{FeOOH} / \mathrm{SO}_{4}$ catalyst was added during Periods 3-6 of condition 1 . Coal conversion during these periods was used as a baseline to compare with the performance of combined $\mathrm{Mo} / \mathrm{Fe}$ catalysts. Starting from period 7 of Condition 2, $100 \mathrm{ppm}$ Molyvan-A catalyst was added to the process. As shown in Figure 16, the addition of Molyvan-A catalyst resulted in an increase in total conversion. At the beginning of condition 3 (Period 11), space velocity was slightly increased. The increase in space velocity did not significantly affect feed conversion. During the last two conditions (Period 11 through 18), $\mathrm{FeOOH} / \mathrm{SO}_{4}$ catalyst containing $70 \mathrm{~W} \%$ water (i.e., in the form of a wet filter cake) was added in an amount equivalent to dry $\mathrm{FeOOH} / \mathrm{SO}_{4}$ used previously. An interesting finding was that iron catalyst, added either as dry powder or wet cake, has the same positive effect on coal conversion. This is a significant finding, as it will not only reduce the cost ofiron catalyst but also help in understanding the catalytic action of $\mathrm{FeOOH} / \mathrm{SO}_{4}$ catalyst in coal liquefaction. 


\section{$524^{\circ} \mathrm{C}+$ RESIDUUM CONVERSION}

Resid conversion measures the ability of the process to convert heavy (high boiling) fractions contained in the feed. For the purpose of calculations, all of the maf portion of the feed coal is considered as $524^{\circ} \mathrm{C}+$ resid in the feed. $524^{\circ} \mathrm{C}+$ resid conversion varied between 82 and $90 \mathrm{~W} \%$ and was more sensitive to the addition of Molyvan-A catalyst and to changes in space velocity than was total coal conversion. Resid conversion during each condition is shown in Figure 17. A comparison of process performance between conditions 1 and 2 indicates that the addition of $100 \mathrm{ppm}$ (and lowering space velocity from 640 to about $416 \mathrm{~kg} / \mathrm{h} / \mathrm{m}^{3}$ reactor) caused about a $7 \mathrm{~W} \%$ increase in $524^{\circ} \mathrm{C}+$ resid conversion. To verify the effect of Molyvan-A catalyst on coal conversion, during periods 11-14 of Condition 3 the process was operated under the same space velocity as Condition 1 but with Molyvan-A added. About a $3 \mathrm{~W} \%$ increase in $524^{\circ} \mathrm{C}+$ resid conversion was observed. Residence time of slurry feed affects $524^{\circ} \mathrm{C}+$ resid conversion. As shown in Figure 17, $524^{\circ} \mathrm{C}+$ resid conversion dropped by about $7 \mathrm{~W} \%$ when the space velocity was increased from $416 \mathrm{~kg} / \mathrm{h} / \mathrm{m} 3$ (Condition 2) to $731 \mathrm{~kg} / \mathrm{h} / \mathrm{m} 3$ (Condition 4). As indicated above, starting from period 11 of Condition 3 , the iron catalyst was added as wet cake (containing $70 \%$ water). The change in $\mathrm{FeOOH} / \mathrm{SO}_{4}$ water content did not have any noticeable influence on resid conversion.

\section{$C_{4} 524^{\circ} \mathrm{C}$ DISTILLATE YIELDS AND SELECTIVITY}

Distillate yields varied between 57 and $64 \mathrm{~W} \%$. As shown in Figure 18 and Table 15, the type of catalyst and space velocity affected distillate yields. A trend similar to that for the resid conversion was observed for distillate yields . The highest distillate yield of $63.6 \mathrm{~W} \%$ was obtained for Condition $2100 \mathrm{ppm}$ of Molyvan-A catalyst and reduced space velocity. Distillate yield dropped slightly when the space velocity was increased from 25.9 to $45.7 \mathrm{~kg} / \mathrm{h} / \mathrm{m} 3$. The lowest distillate yield was obtained in condition 1 when $\mathrm{FeOOH} / \mathrm{SO}_{4}$ alone was the dispersed catalyst. An important implication may be that the combined system of Mo and $\mathrm{Fe}$ catalysts is effective in upgrading polyaromatic structures and breaking strong C-C bonds in coal. Also shown in Figure 19 is the selectivity of distillates for all conditions. The distillates, in general, contained $30 \mathrm{~W} \%$ naphtha and $40 \mathrm{~W} \%$ of middle distillate. Middle distillate $\left(177-343^{\circ} \mathrm{C}\right)$ yield followed a trend similar to that for overall distillate yield.

\section{HYDROGEN CONSUMPTION}

Hydrogen consumption based on $\mathrm{mf}$ feed, varied between 4.4 and $7.5 \mathrm{~W} \%$. The highest hydrogen consumption was observed for Condition 2 with Molyvan-A catalyst and reduced space velocity (Figure 20). Middle distillate and gas yield for Condition 2 were also the highest, indicating that extensive hydrocracking occurred. On raising space velocity, the hydrogen consumption decreased together with the reduction in the formation of gases. Lower hydrogen consumption for Condition-4 did not affect distillate yields significantly. 


\section{$\mathrm{C}_{1}-\mathrm{C}_{3}$ GAS YIELDS}

As shown in Figure 21, normalized $\mathrm{C}_{1}-\mathrm{C}_{3}$ gas yield for CMSL-10 varied between 10.9 and $15.7 \mathrm{~W} \%$. The highest yield $(15.7 \mathrm{~W} \%$ ) was obtained during periods $7-9$ of Condition 2 , with Molyvan-A catalyst and reduced space velocity. It is interesting that the formation of $\mathrm{C}_{1}-\mathrm{C}_{3}$ gases followed a trend similar to that for hydrogen consumption. Gas yield was reduced during the last condition which was at the highest space velocity. This suggests that the high gas yields can be reduced by reducing residence time.

\section{$524^{\circ} \mathrm{C}+\mathrm{RESIDUUM}$ YIELD}

$524^{\circ} \mathrm{C}+$ residue yields for CMSL- 10 varied between 4 and $12 \mathrm{~W} \%$, as indicated in Figure 22. The addition of Molyvan-A catalyst reduced the residuum yields due to the strong hydrocracking ability of Molyvan-A catalyst. An increase in residuum yield was observed on raising space velocity.

\section{PRODUCT QUALITY}

Various fractions (First-Stage/Second-Stage Vent Gases, CAS Bottoms, SOH, PFL and PFS/VSB) from work-up periods $6,9,14$ and 18 were analyzed in detail. The results of these analyses are summarized in Tables 16 through 20.

\section{Separator Overhead Product (SOH)}

$\mathrm{SOH}$ oil represents the net light distillate (IBP-750 $\mathrm{F}$ ) from CMSL-10. Properties of $\mathrm{SOH}$ oil for the work-up periods are shown in Table $16 . \mathrm{SOH}$ oil had a typical boiling range of $54-399^{\circ} \mathrm{C}$. The IBP $-177^{\circ} \mathrm{C}$ Fraction, the lightest fraction of the SOH oil, is almost the same for all conditions. The API gravities (an indication of paraffinic character) of the $\mathrm{SOH}$ oil for all workup period were high (>34). The heteroatoms level (nitrogen and sulfur) were below $50 \mathrm{ppm}$ throughout the run, indicating very successful operation of the in-line hydrotreater. The change of space velocity and addition of Molyvan-A catalyst did not affect the SOH distillation.

\section{Pressure Filter Liquid (PFL)}

Pressure filter liquid (PFL) represents the liquid (oil) part of the atmospheric still (CAS) bottoms. In CMSL-10, CAS bottoms was not used as recycle solvent; only the solids-free PFL was used as recycle oil. As shown in Table 17, PFL has a broad boiling range. The IBP of the PFL for all conditions is about $243^{\circ} \mathrm{C}$. As shown in Figure 23, toluene solubles in the PFL varied from 84 to $94 \mathrm{~W} \%$, while cyclohexane soluble varied from 60 to $70 \mathrm{~W} \%$. The yield of the high boiling fraction $\left(524^{\circ} \mathrm{C}+\right.$ ) varied from 34 to $46 \mathrm{~W} \%$, depending on process conditions. A large portion of the $524^{\circ} \mathrm{C}+\mathrm{PFL}$ was toluene soluble ( $70 \mathrm{~W} \%$ ). As shown in Table 17, the yield of the 
$975^{\circ} \mathrm{F}+$ fraction was reduced upon addition of Molyvan-A catalyst. Space velocity also positively affected the $524^{\circ} \mathrm{C}+$ content of the PFL. The addition of Molyvan-A catalyst resulted in an increase in the $\mathrm{H} / \mathrm{C}$ ratio, indicating that Molyvan-A catalyst has a good hydrogenation function.

\section{INTERSTAGE SAMPLES}

Interstage samples were withdrawn from the ebullating line on the first stage coal liquefaction reactor. The properties of these samples shed light on the performance of the first stage reactor. Interstage samples of the product slurry from the first stage reactor were collected during all the work-up periods of CMSL-10 (Tables 19 and 20). The pressure filter solids from the first stage were analyzed, and it indicated that 91-93.5 W\% maf of coal conversion was achieved after the first stage. The toluene soluble portion of the $524^{\circ} \mathrm{C}+$ fraction is about $80 \mathrm{~W} \%$. The overall resid content of the PFL varied between 36-45 w\%. Comparison between Periods 14 and 18 interstage PFL analyses indicates that increased space velocity did not affect PFL quality significantly.

\section{EXTERNAL SAMPLES}

As mentioned earlier, a number of samples of various process streams were obtained (for further detailed characterization and products assessment) for the Consol, Inc. and for members of the Consortium of Fossil Fuel Liquefaction Science. These samples, their amounts, and the operating periods when these were withdrawn are shown in Table 21. 


\section{CONCLUSIONS}

After 18 periods of continuous operation, CMSL-10 was successfully completed with one brief shut-down. The results demonstrated that the combination of $\mathrm{Mo}$ and $\mathrm{FeOOH}$ catalysts improved process performance. (Iron alone was not very effective a catalyst.) It was found that process performance remained the same whether iron catalyst $\left(\mathrm{FeOOH} / \mathrm{SO}_{4}\right)$ was added dry or as wet cake containing $70 \mathrm{~W} \%$ water. This discovery should reduce catalyst costs by $30 \%$ due to the elimination of two time consuming and expensive processing steps in catalyst preparation. Space velocity and catalyst type had an impact on $524^{\circ} \mathrm{C}+$ conversion and distillate yield but did not seem to affect total conversion. A slight change in the quality of SOH and PFL was observed upon changing space velocity. This suggests that the process can be operated at even higher throughput. In-line hydrotreating was very effective for the removal of heteroatoms and for hydrogenation. The use of an in-line hydrotreatior has resulted in the production of high quality distillates which contain less than $50 \mathrm{ppm}$ each of sulfur and nitrogen. Analysis of samples from various process streams indicated that the current reactor configuration and combined system of Mo and Fe catalysts are effective in producing quality products from coal liquefaction. It is possible to establish an effective process for coal liquefaction using a suitable combination of iron and molybdenum in low concentrations $(5000 \mathrm{ppm}$ for iron and $50-100 \mathrm{ppm}$ for molybdenum) so that these dispersed catalysts can be employed on a disposable basis.

\section{RECOMMENDATIONS FOR FUTURE WORK}

Based upon the results from bench runs CMSL-09 and CMSL-10, it is strongly recommended that a slurry catalyst system, comprising iron and molybdenum, be optimized. In the past two bench runs, iron and molybdenum were added from different sources; it will be interesting to determine how well a bimetallic catalyst additive, consisting of both iron and molybdenum in the same formulation, performance under comparable process conditions. The HTI's iron catalyst preparation is easily amenable for incorporation of any other metal(s) into the catalyst formulation. For the first time during CMSL-10, it was found that a wet filter cake consisting of about $70 \%$ water is almost as effective as the dried form of the iron catalyst. Wet cake catalyst addition, which is much more economical than the dry powder addition, should be looked into in more detail and should be optimized. The iron-molybdenum dispersed catalyst combination should be studied for coprocessing of coal with heavy resids and waste organics (plastics). 
TABLE 14

\section{CMSL-10 OPERATING CONDITIONS}

Black Thunder Coal (HRI-6213: POC-02 coal, dried to about 11\% moisture)

Back Pressure: 2500 psig

Catalyst: Dispersed Fe and Mo Catalysts \& C-411 in HTU

\section{Condition \\ Periods \\ Dates}

Work-up Periods

Temperatures, $\mathbf{C}$

$\begin{array}{ll}\text { Pretreater } & 300 \\ \text { Reactor K-1 } & 440 \\ \text { Reactor K-2 } & 449 \\ \text { Hydrotreater } & 379\end{array}$

Space Velocity,

$\mathrm{kg} \mathrm{coal} / \mathrm{h} / \mathrm{m} 3$ reactor

Solvent/Coal Ratio

Dispersed Catalysts, ppm

HTI Fe Catalyst Molyvan-A

Recycle

H2S Additive,

$w \%$ dry coal
640

1

5000

0

PFL

$\begin{array}{cc}1 & 2 \\ 3-6 & 7-9 \\ 06 / 13-16 / 95 & 06 / 17-19 / 1995 \\ 5 & 9\end{array}$

300

440

449

379

480

1

5000

100

PFL

3
3
$10-14$
$06 / 20-25 / 95$

14

300

440

449

379

640

1

5000

100

PFL
100

PFL

4

$06126-2$

18

300

449

460

379

800

1

5000

3 
TABLE 15

\section{CMSL-10: PROCESS PERFORMANCE SUMMARY}

\begin{tabular}{|c|c|c|c|c|}
\hline Unit & 227 & 227 & 227 & 227 \\
\hline Run & 88 & 88 & 88 & 88 \\
\hline Condition & 1 & 2 & 3 & 4 \\
\hline Period Number & 6 & 9 & 14 & 18 \\
\hline Hours of Run (end of Period) & 144 & 216 & 336 & 432 \\
\hline Disp. Cat. ppm: Fresh Mo & 0 & 100 & 100 & 100 \\
\hline $\begin{array}{r}\text { Fresh Iron } \\
\text { Stage I Feed Space Velocity }\end{array}$ & 5000 & 5000 & 5000 & 5000 \\
\hline $\begin{array}{l}\mathrm{kg} \text { coal/hr/m3 reactor vol. } \\
\text { Temperatures, C }\end{array}$ & 659.2 & 414.4 & 654.4 & 731.2 \\
\hline Pretreater & 303 & 302 & 304 & 302 \\
\hline $\mathrm{K}-1$ & 443 & 441 & 444 & 449 \\
\hline $\mathrm{K}-2$ & 450 & 448 & 451 & 457 \\
\hline Total Material Recovery \% (Gross) & 100.2 & 103.5 & 102.2 & 100.9 \\
\hline \multicolumn{5}{|l|}{$\begin{array}{l}\text { ESTIMATED NORMALIZED YIELDS: } \\
\text { W\% DRY Coal }\end{array}$} \\
\hline C1-C3 in Gases & 13.37 & 15.71 & 12.20 & 10.95 \\
\hline C4-C7 in Gases & 4.35 & 5.63 & 4.56 & 3.79 \\
\hline IBP-177 deg C & 12.35 & 15.78 & 12.81 & 12.75 \\
\hline $177-260 \mathrm{deg} C$ & 10.61 & 11.70 & 9.69 & 11.13 \\
\hline $260-343 \operatorname{deg} C$ & 11.67 & 15.79 & 13.96 & 13.73 \\
\hline $343-454$ deg C & 11.84 & 9.50 & 12.73 & 13.21 \\
\hline $454-524 \operatorname{deg} C$ & 2.65 & 1.55 & 3.39 & 4.02 \\
\hline 524 deg $C+$ & 8.76 & 4.00 & 8.60 & 11.52 \\
\hline Unconverted Feed & 7.66 & 5.34 & 5.16 & 3.26 \\
\hline Water & 10.91 & 10.41 & 10.96 & 9.27 \\
\hline$-\operatorname{cox}$ & 5.68 & 5.36 & 5.63 & 3.89 \\
\hline $\mathrm{NH} 3$ & 0.87 & 1.03 & 0.86 & 0.73 \\
\hline $\mathrm{H} 2 \mathrm{~S}$ & -0.17 & -0.08 & -0.19 & 0.08 \\
\hline Hydrogen Consumption & 6.30 & 7.45 & 6.12 & 4.09 \\
\hline
\end{tabular}

PROCESS PERFORMANCE, maf Coal

Coal Conversion

91.9

94.3

94.5

96.5

$524 \mathrm{C}+$ Conversion

82.5

90.1

85.4

84.0

C4-524 C Distillate Yield

56.7

63.6

60.6

62.2

*The first two run conditions employed a dry/powdered form of iron catalyst, while the last two employed iron catalyst in the form of a wet filter cake. 


\section{TABLE 16}

CMSL-10: SEPARATOR OVERHEAD (SOH) PROPERTIES

$\begin{array}{llcccc}\text { Unit } & & 227 & 227 & 227 & 227 \\ \text { Run } & & 88 & 88 & 88 & 88 \\ \text { Condition } & & 1 & 2 & 3 & 4 \\ \text { Period Number } & & 6 & 9 & 14 & 18 \\ \text { Gravity, API } & & 38 & 34 & 35.9 & 35.4 \\ \text { IBP, deg C } & & 60.0 & 55.0 & 55.0 & 53.9 \\ \text { FBP, deg C } & & 372.2 & 378.9 & 375.6 & 363.3 \\ & & & & & \\ \text { ASTM D-86 Distillation, Composition } & & & & \\ & \text { W\% IBP-177 deg C } & 35.2 & 33.5 & 35.5 & 35.8 \\ & \text { W\% 177-260 deg C } & 27.9 & 25 & 26.4 & 30.2 \\ & \text { W\% 260-343 deg C } & 25.2 & 31.1 & 28.8 & 26.7 \\ & \text { W\% 343 deg C+ } & 10.8 & 9.7 & 8.5 & 7.2 \\ & \text { W\% Loss } & 0.9 & 0.7 & 0.8 & 0.1 \\ \text { Elemental Analysis } & & & & & \\ & & & & & \\ & & 86.42 & 87.2 & 86.84 & 87.22 \\ & \text { Carbon, W\% } & 13.44 & 12.75 & 12.96 & 12.59 \\ & \text { Hydrogen, W\% } & 10.6 & 53 & 46 & 29 \\ \text { H/C RATIO } & \text { Sulfur (Antek), ppm } & <0.5 & 55 & 53 & 63 \\ & \text { Nitrogen (Antek), ppm } & 1.87 & 1.75 & 1.79 & 1.73\end{array}$


TABLE 17

\section{CMSL-10: PROPERTIES OF THE PRESSURE FILTER LIQUID (2nd STAGE)}

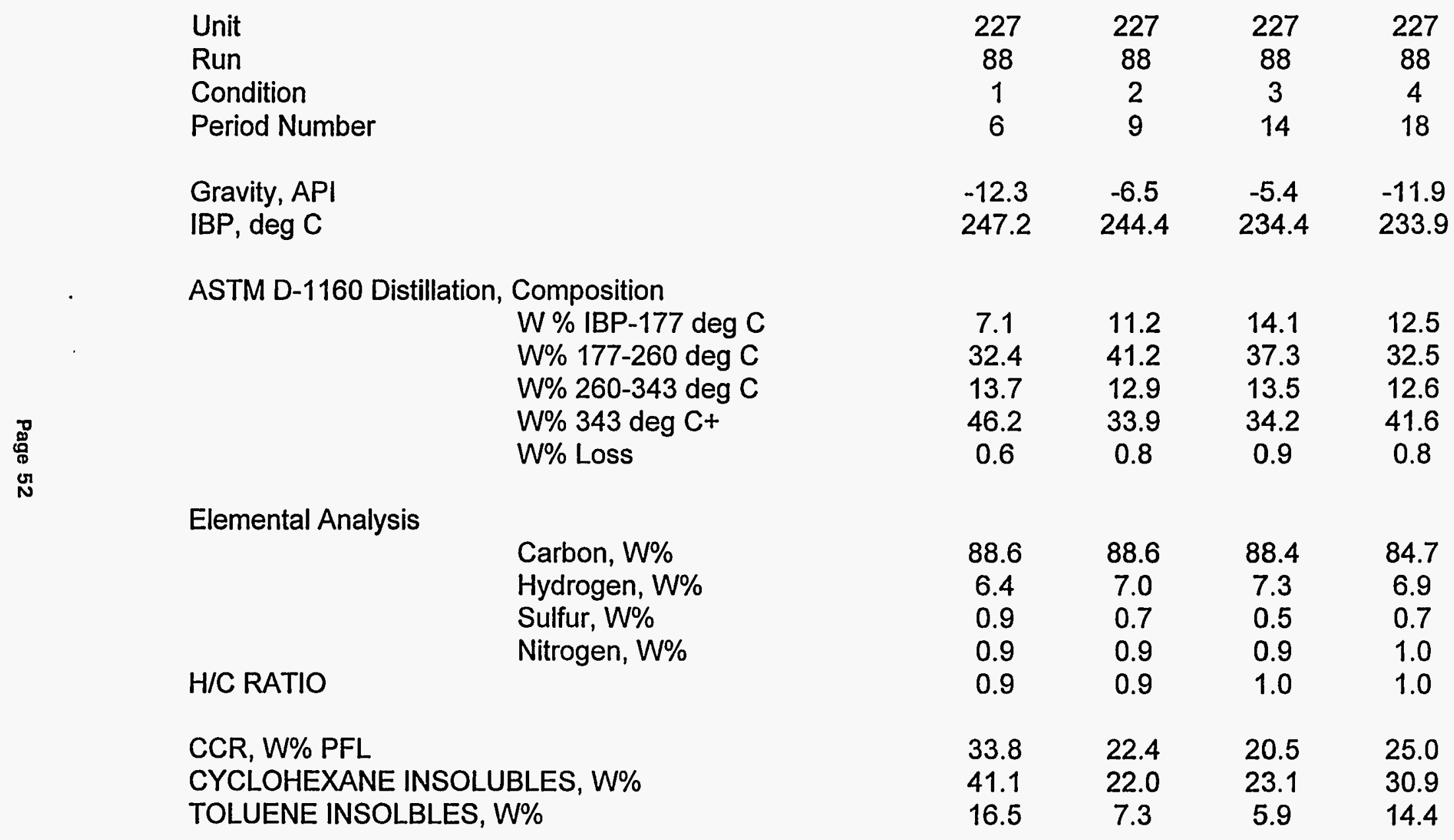


TABLE 18

CMSL-10: INSPECTION,OF THE PRESSURE FILTER SOLIDS (2nd STAGE)

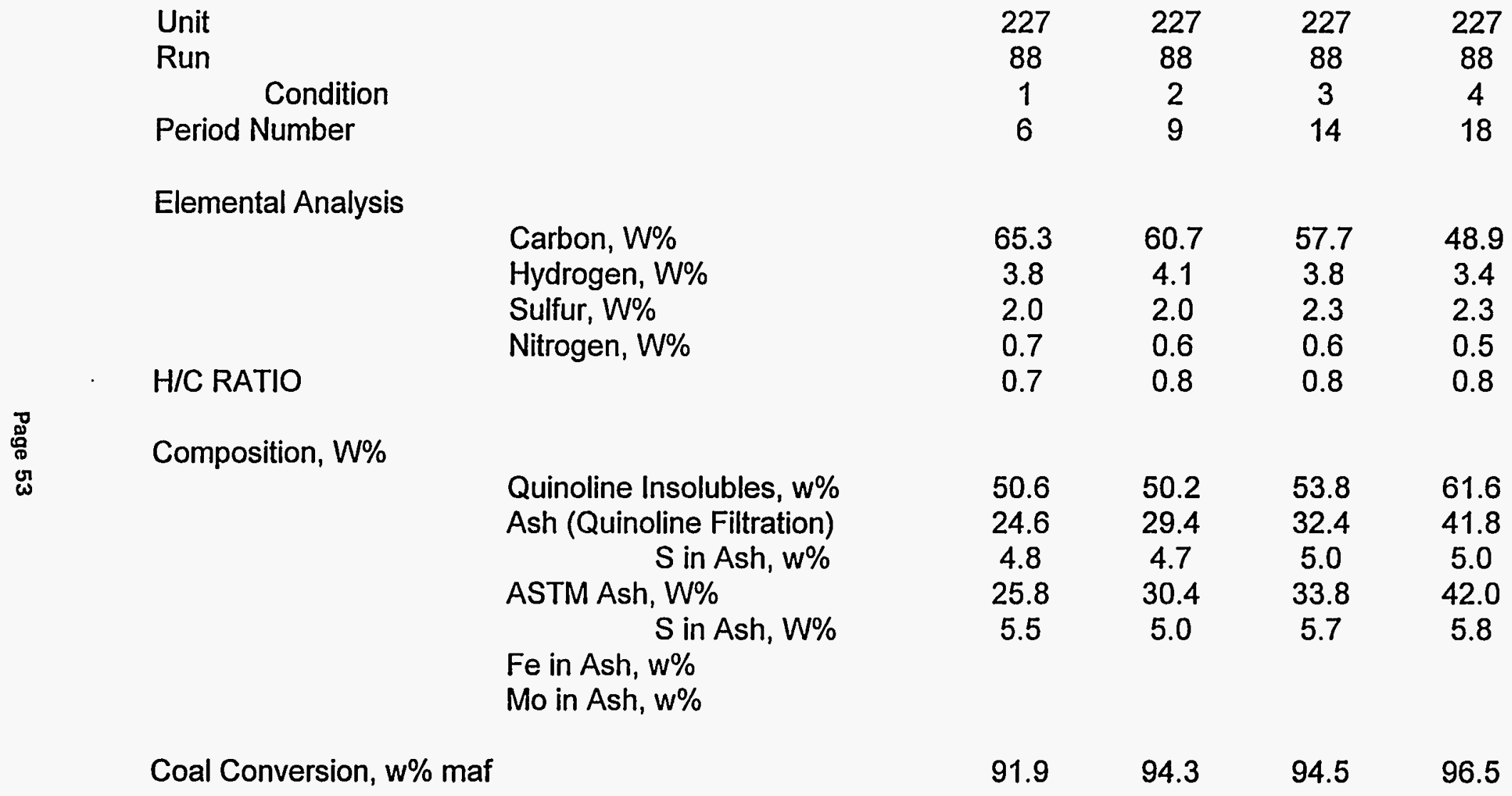


TABLE 19

CMSL-10: PROPERTIES OF THE FIRST STAGE PRESSURE FILTER LIQUID

Unit

Run

Condition

Period Number*

Gravity, API

IBP, deg C

ASTM D-1160 Distillation, Composition

W \% IBP-177 deg C

W\% 177-260 deg C

W\% 260-343 deg C

W\% 343 deg C+

W\% Loss

Elemental Analysis

Carbon, W\%

Hydrogen, W\%

Sulfur, W\%

Nitrogen, W\%

H/C RATIO

CCR, W\% PFL

CYCLOHEXANE INSOLUBLES, W\%

TOLUENE INSOLBLES, W\%
227

88

2

9

$-5.6$

234.4

11.9

34.3

16.9

36.3

0.6

89.2

7.3

0.7

0.8

1.0

23.0

25.9

8.0
227

88

3

14

$-7.9$

265.6

6.9

32.8

14.4

45.3

0.6

88.9

6.7

0.5

1.1

0.9

26.2

30.5

9.1
227

88

4

18

$-8.9$

255.0

8.7

32.2

14.2

44.3

0.6

89.2

7.1

0.5

1.0

1.0

28.8

37.0

9.1

*Period 6 interstage sample could not be pressure filtered due to its highly viscous nature. 
TABLE 20

CMSL-10: INSPECTION OF THE FIRST STAGE PRESSURE FILTER SOLIDS

Unit

227

88

Condition

Period Number

2

9

227

88

3

14

227

88

4

18

Elemental Analysis

Carbon, W\%

65.3

4.3

Hydrogen, W\%

2.0

Sulfur, W\%

0.8

Nitrogen, W\%

0.8

63.9

4.4

2.0

0.8

0.8

54.1

3.9

2.0

0.5

HIC RATIO

0.9

Composition, W\%

Quinoline Insolubles, W\%

50.7

23.4

51.1

58.0

Ash (Quinoline Filtration)

24.2

26.6

ASTM Ash, W\%

$S$ in Ash, W\%

5.0

26.7

5.7

39.0

35.7

91.8

93.0

9.0

93.6 
TABLE 21

\section{Hydrocarbon Technologies, Inc. \\ SHIPPING REQUEST FORM}

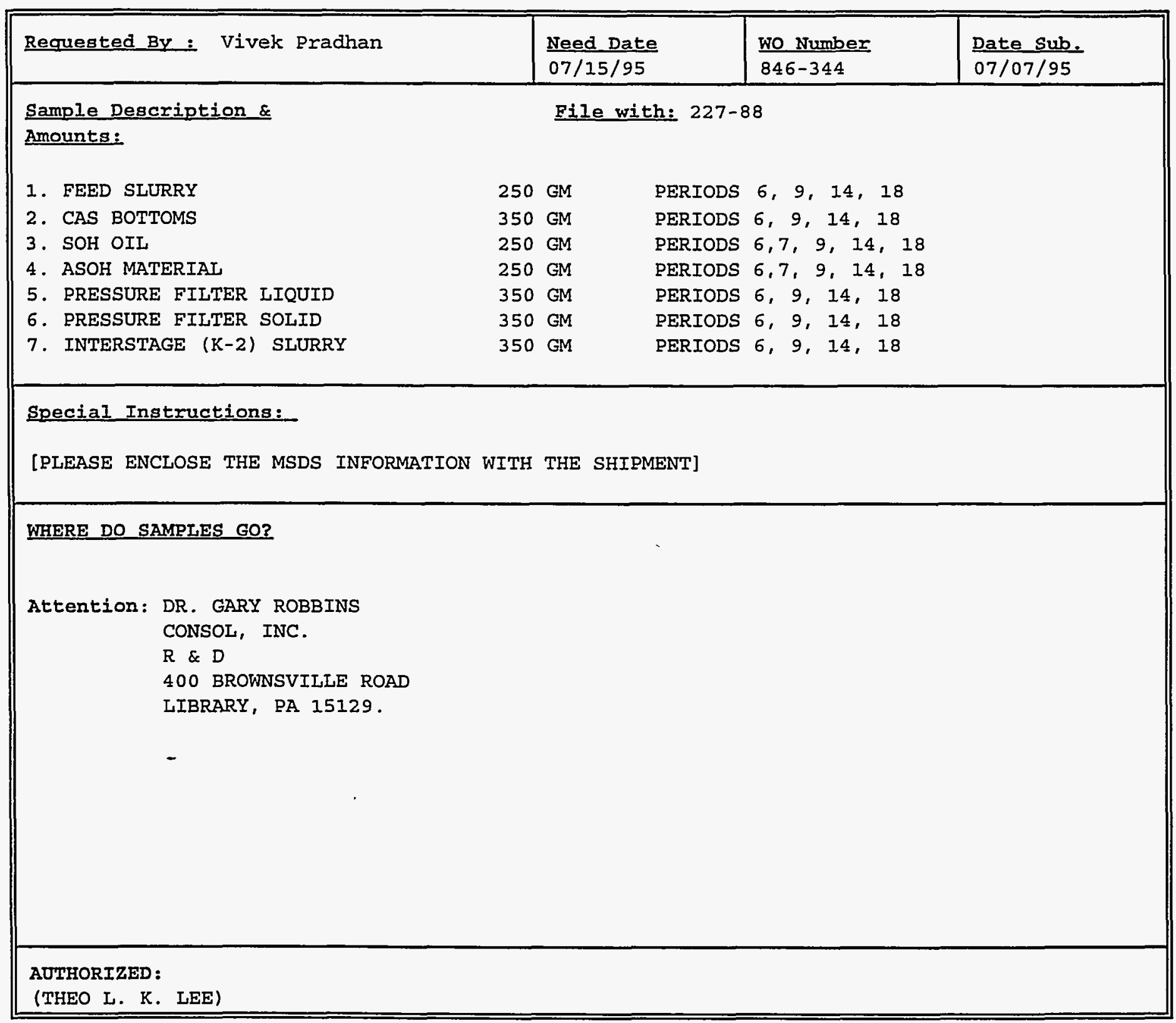




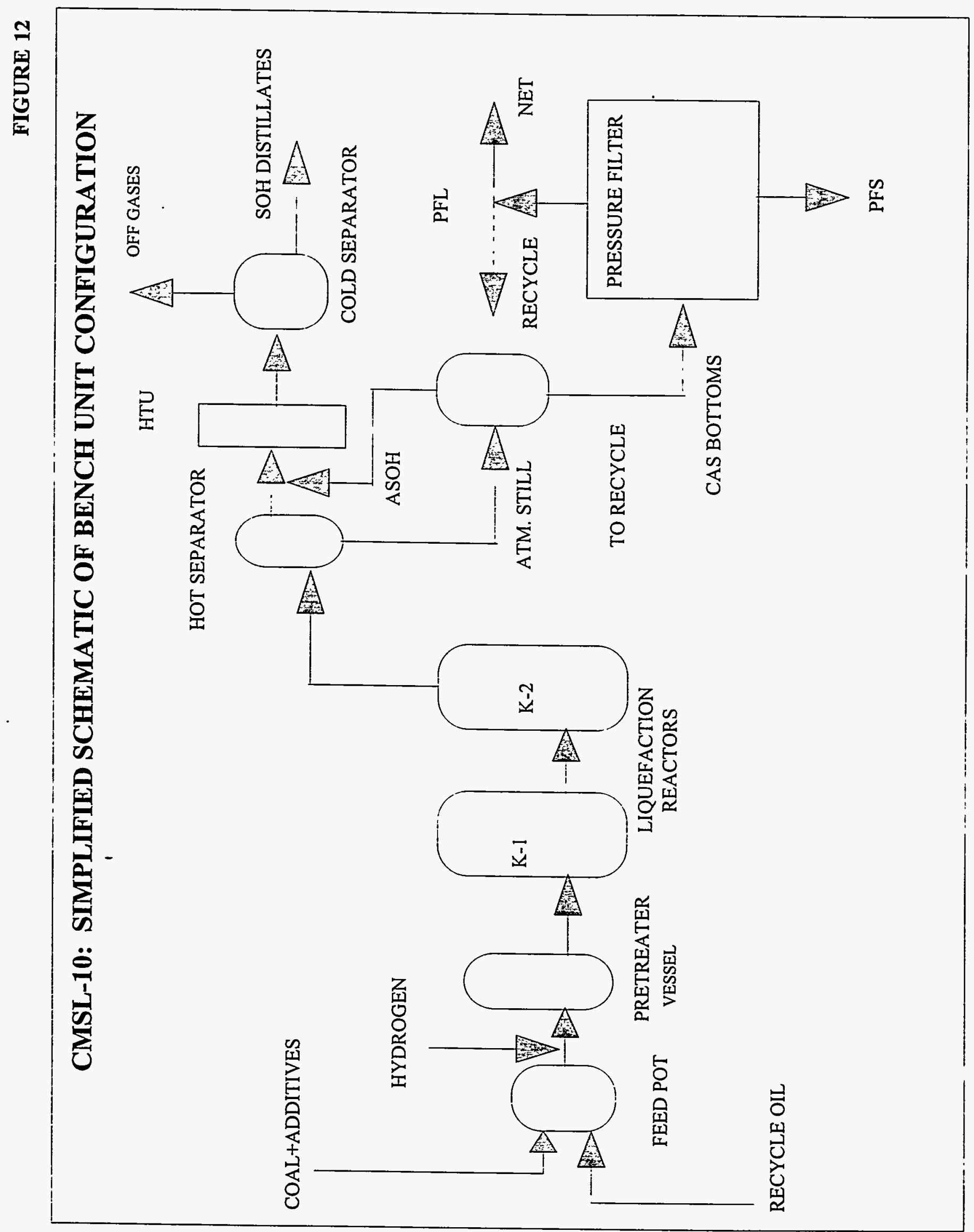

Page 57 


\section{CMSL-10: Daily Material Balance}

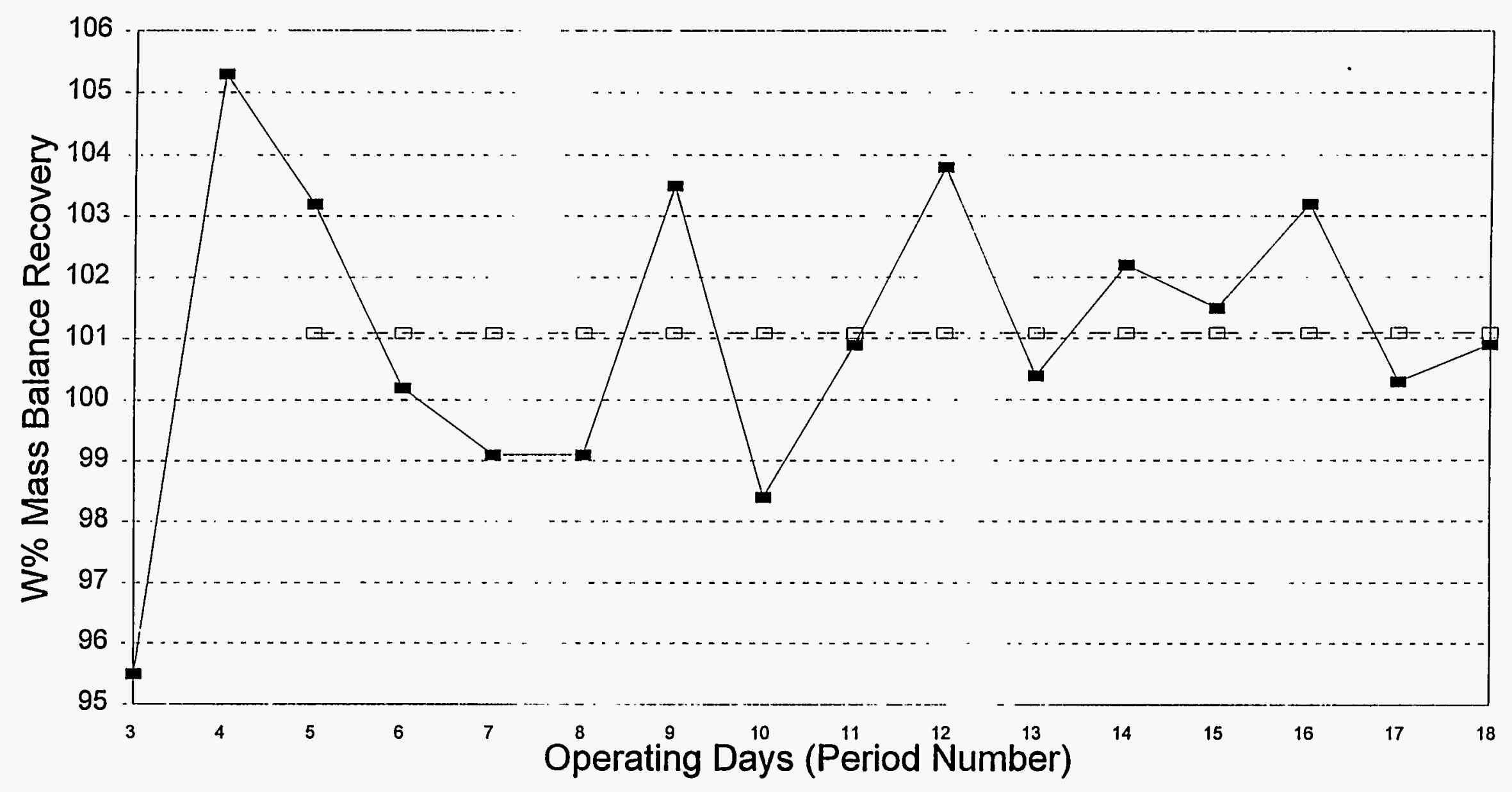

$\rightarrow$ Daily Recovery $\quad-\square-$ Average Recovery 


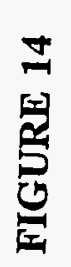

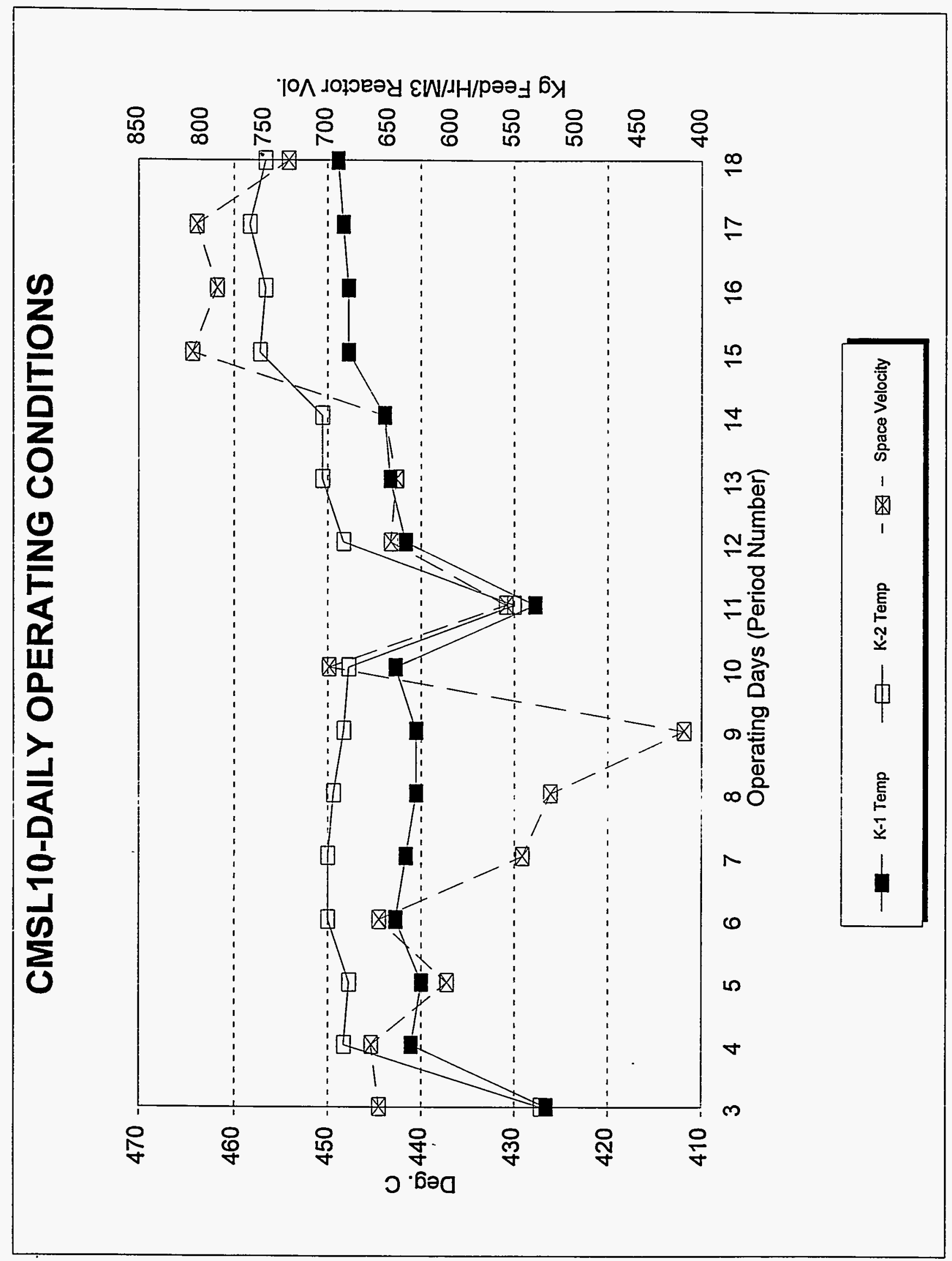

Page 59 


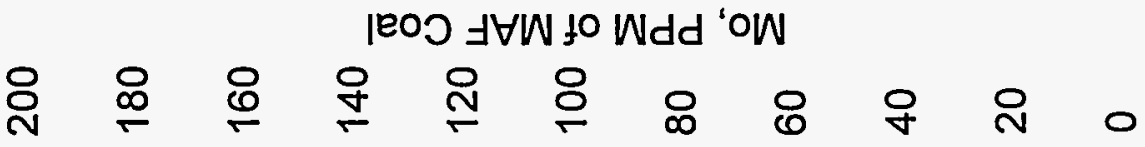
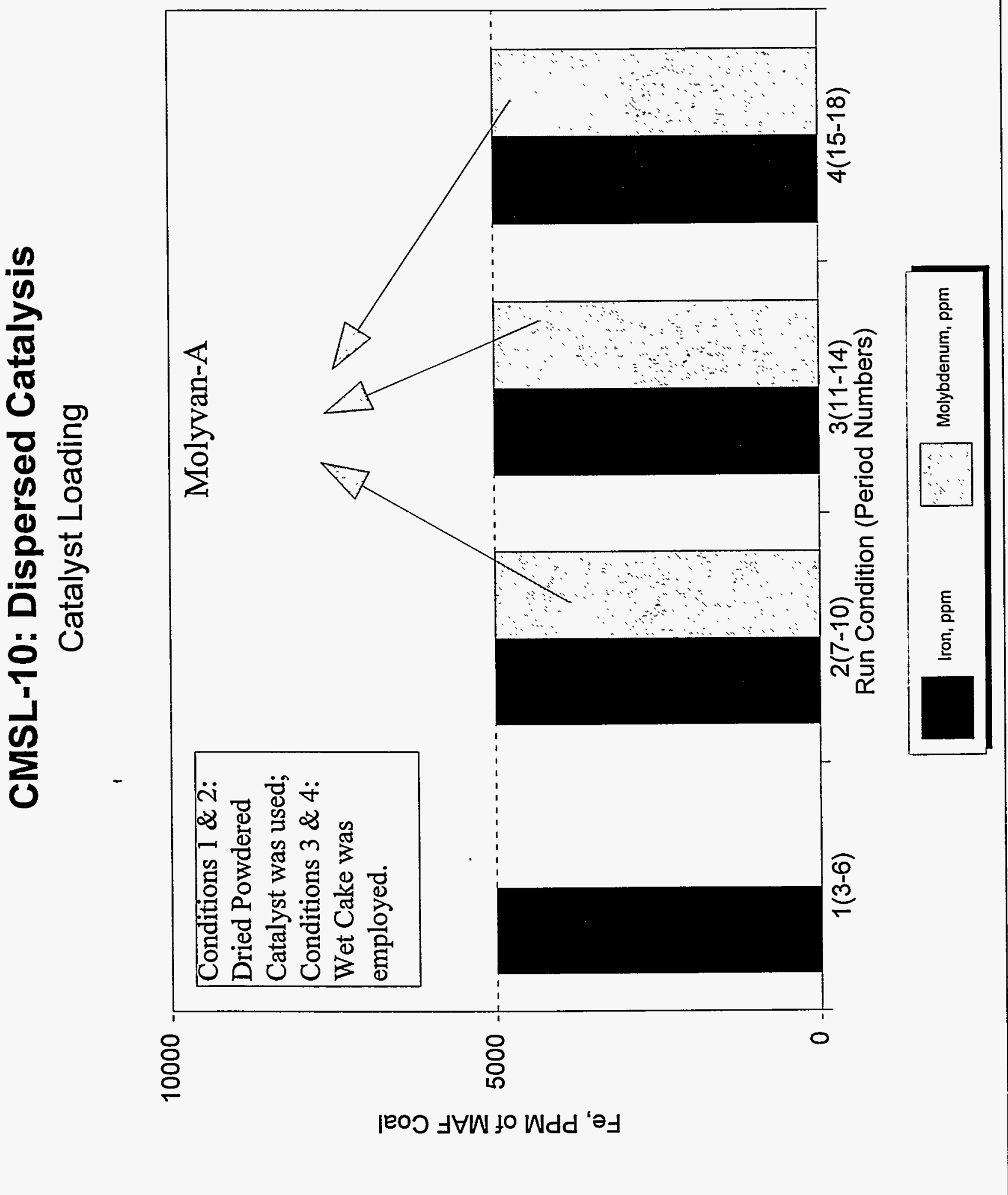


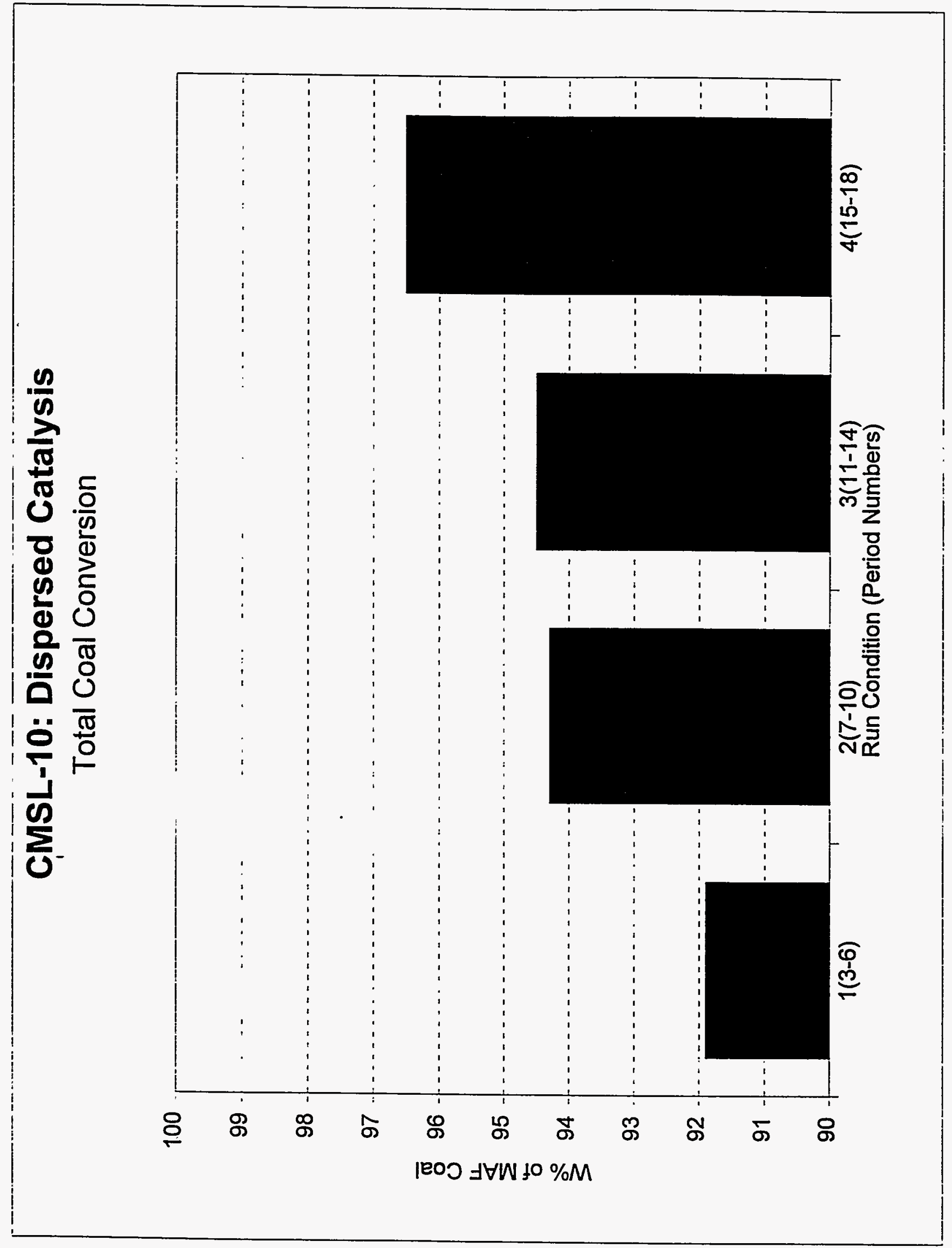

Page 61 


\section{CMSL-10: Dispersed Catalysis}

Total $524 \mathrm{C}+$ Resid Conversion

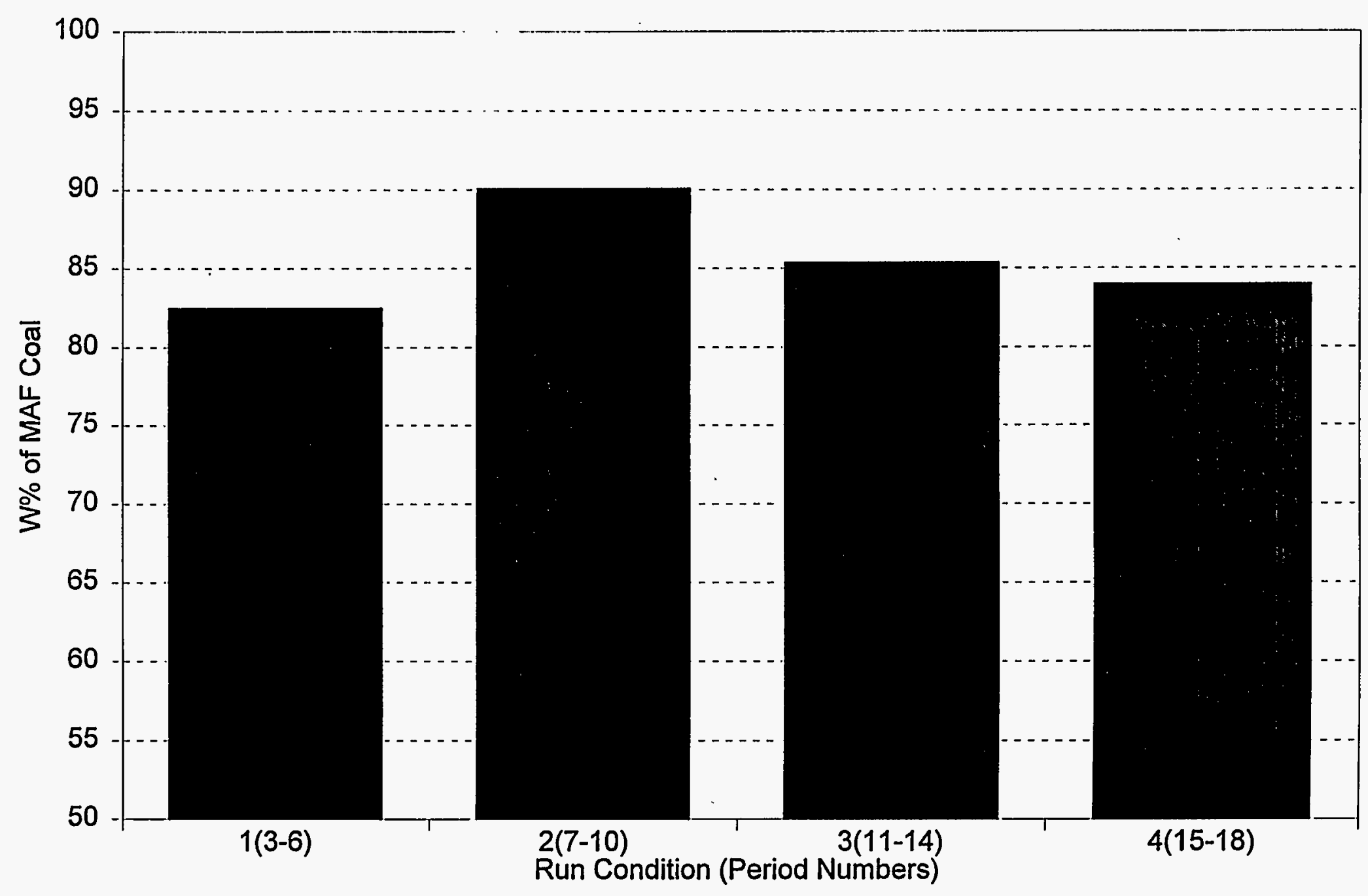




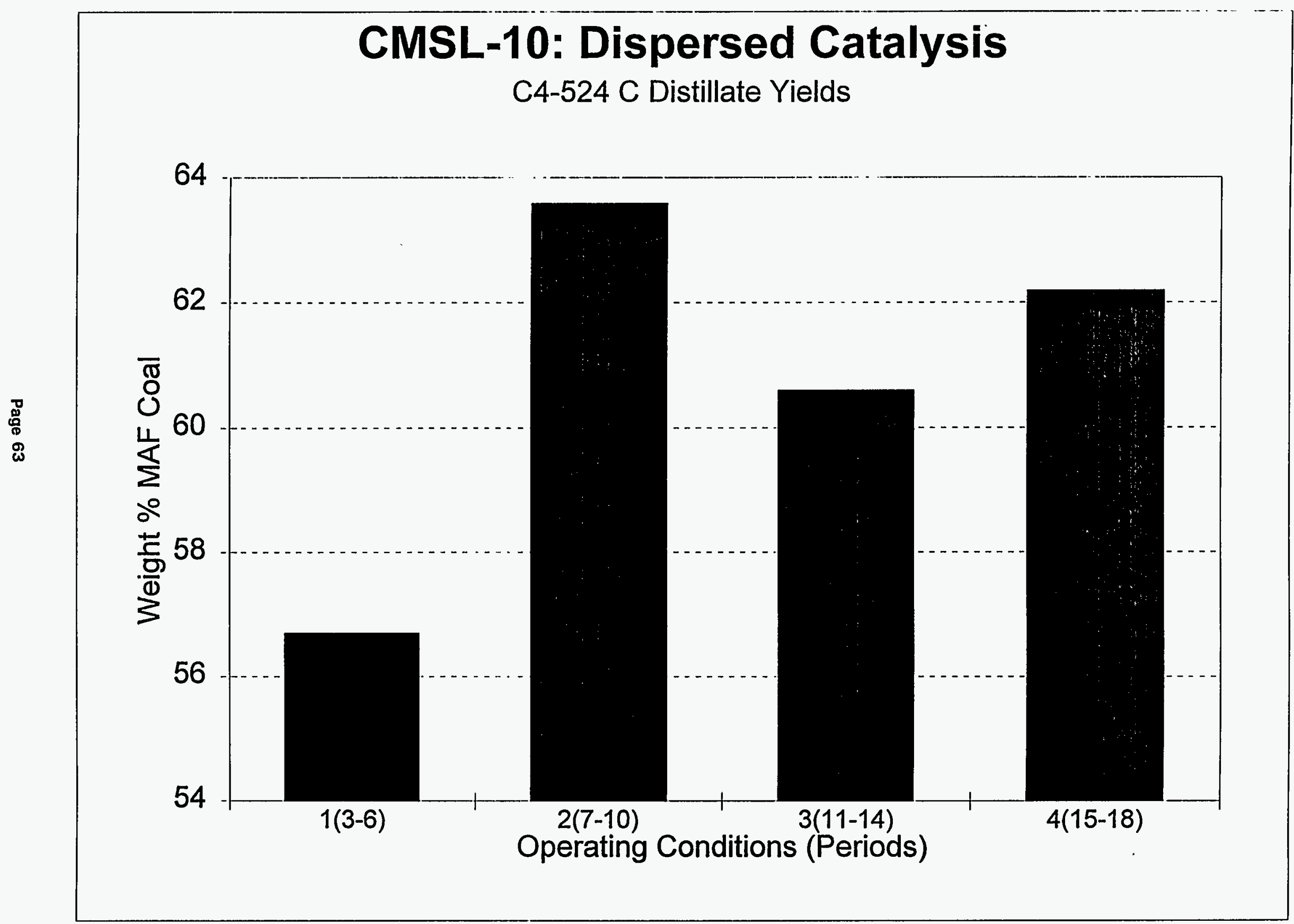




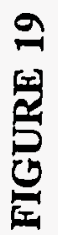

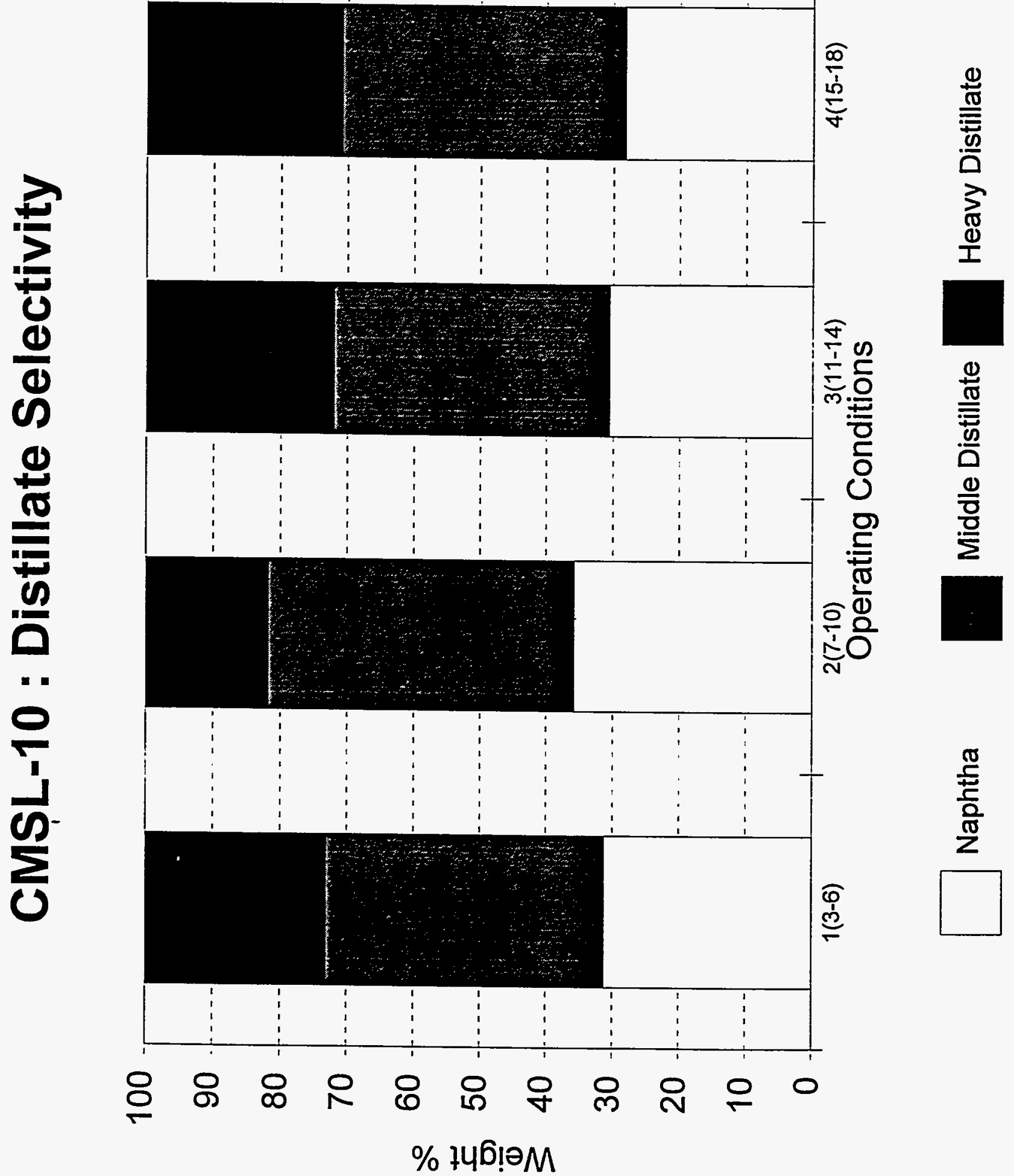




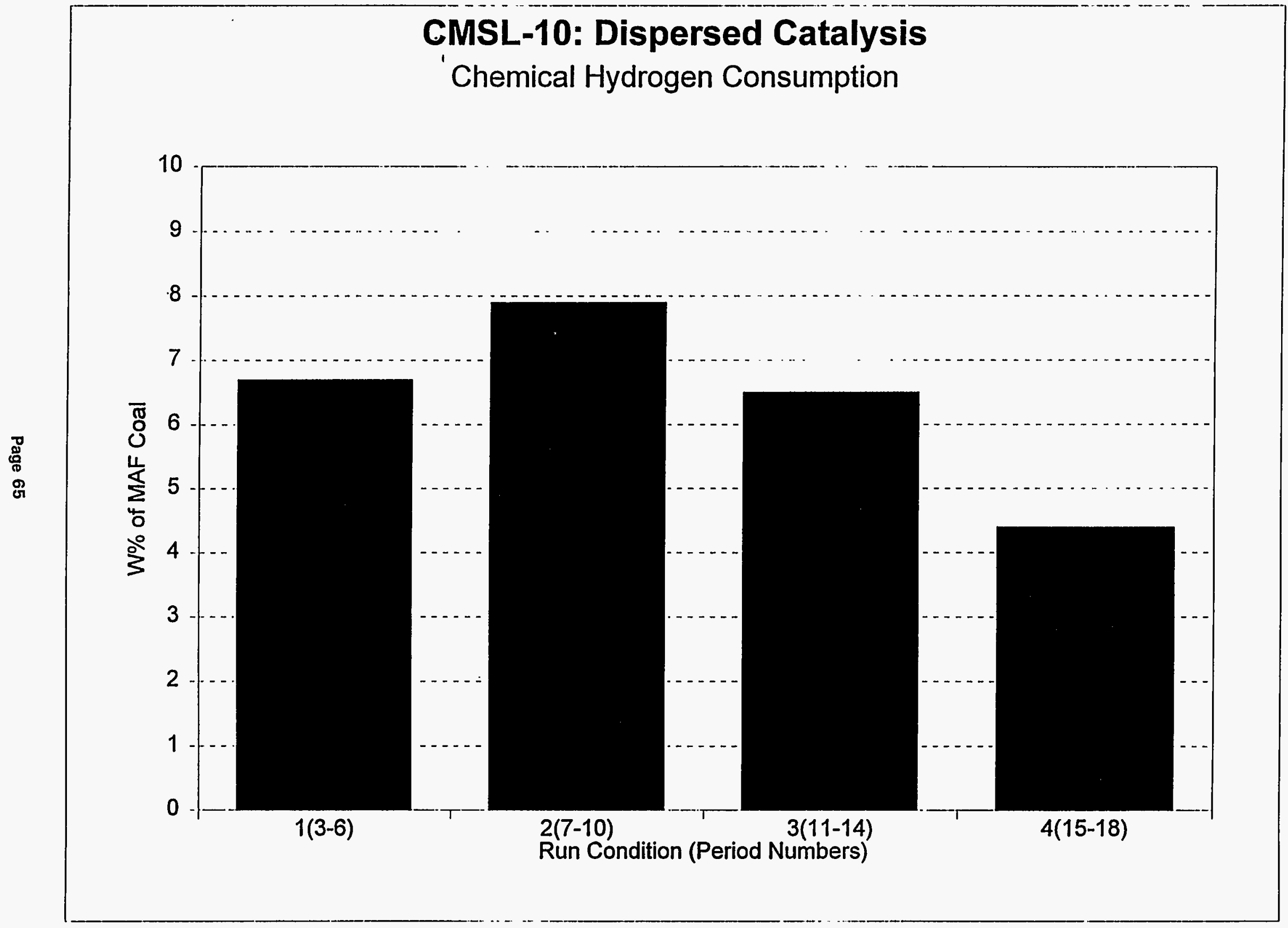




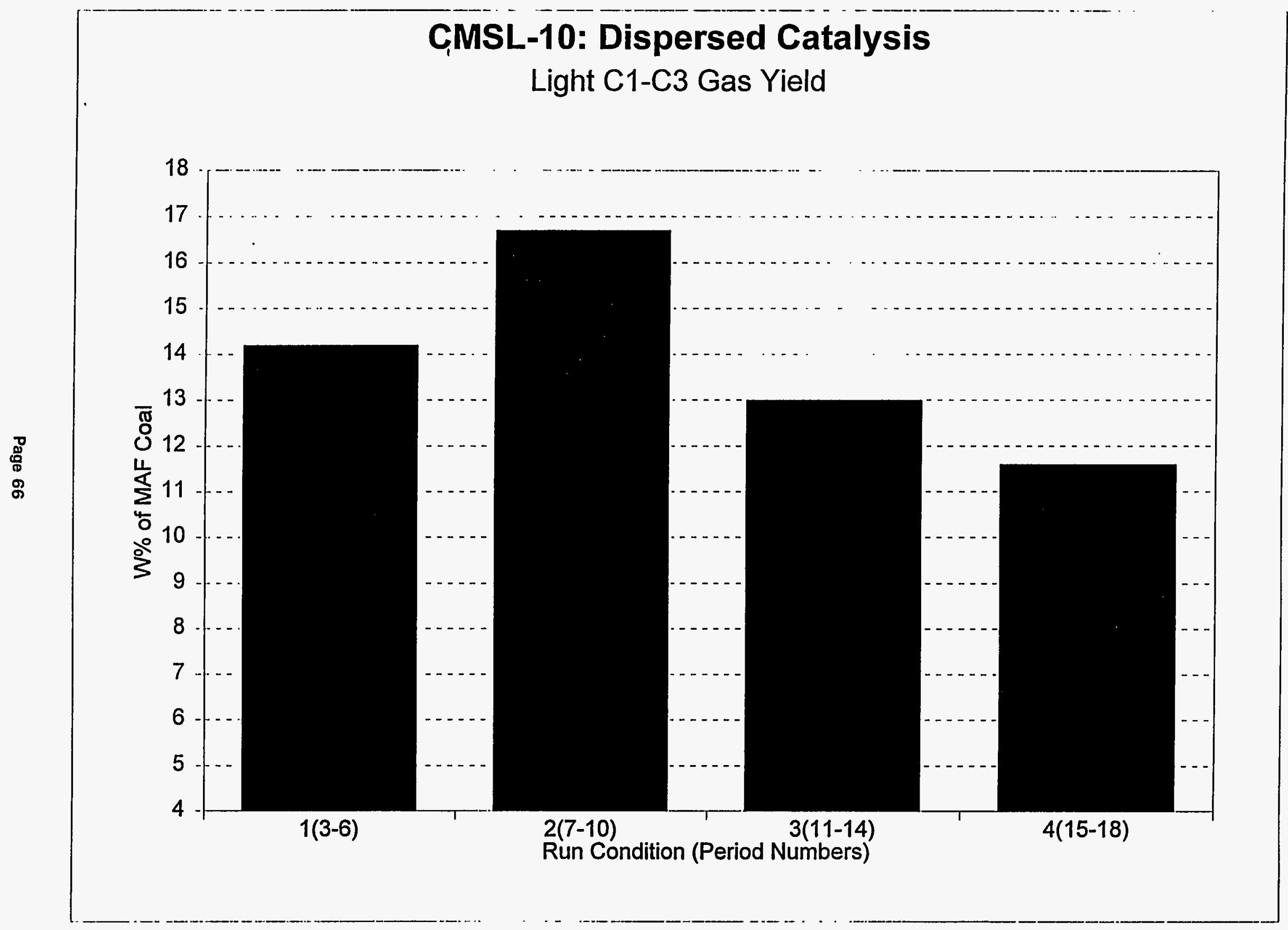


공
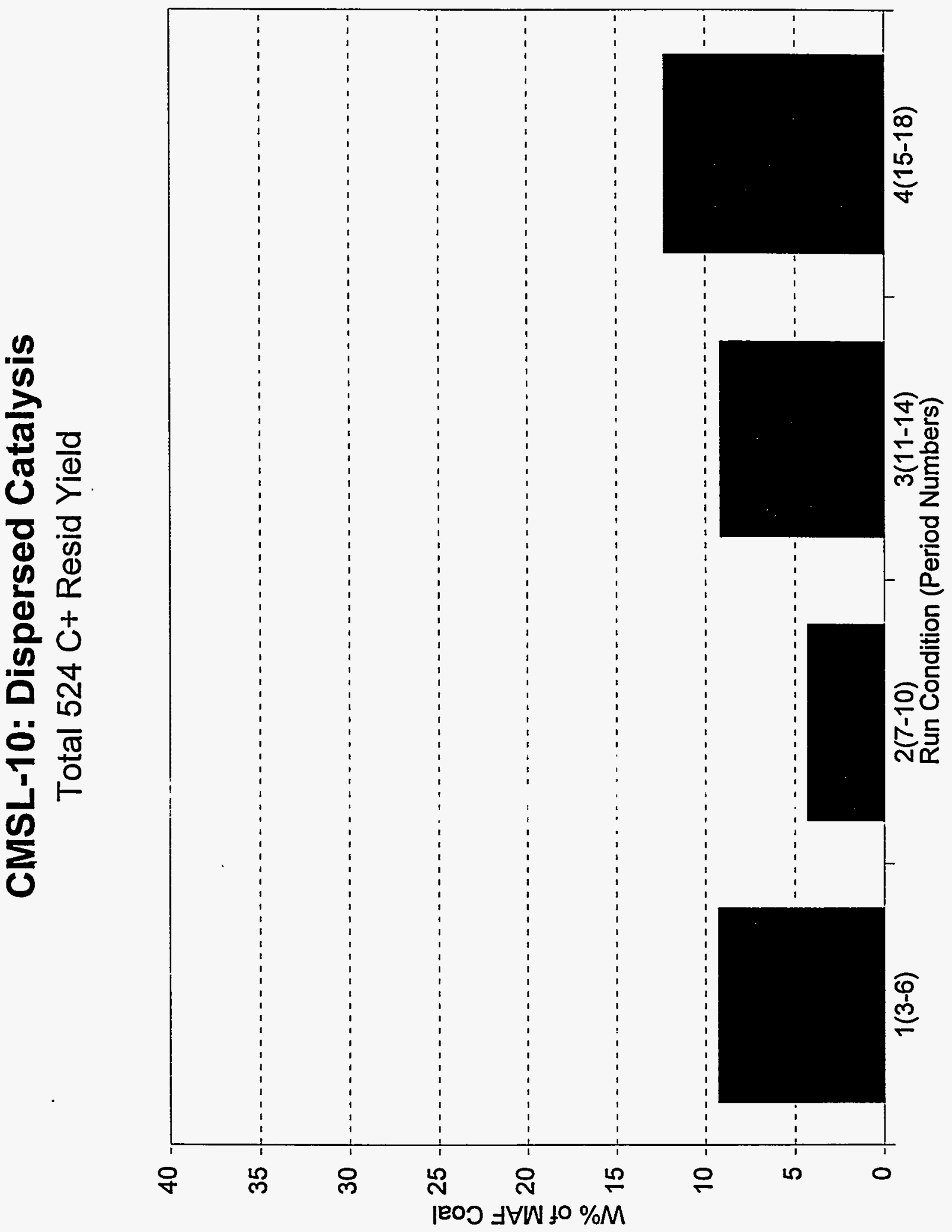

Page 67 
FIGURE 23

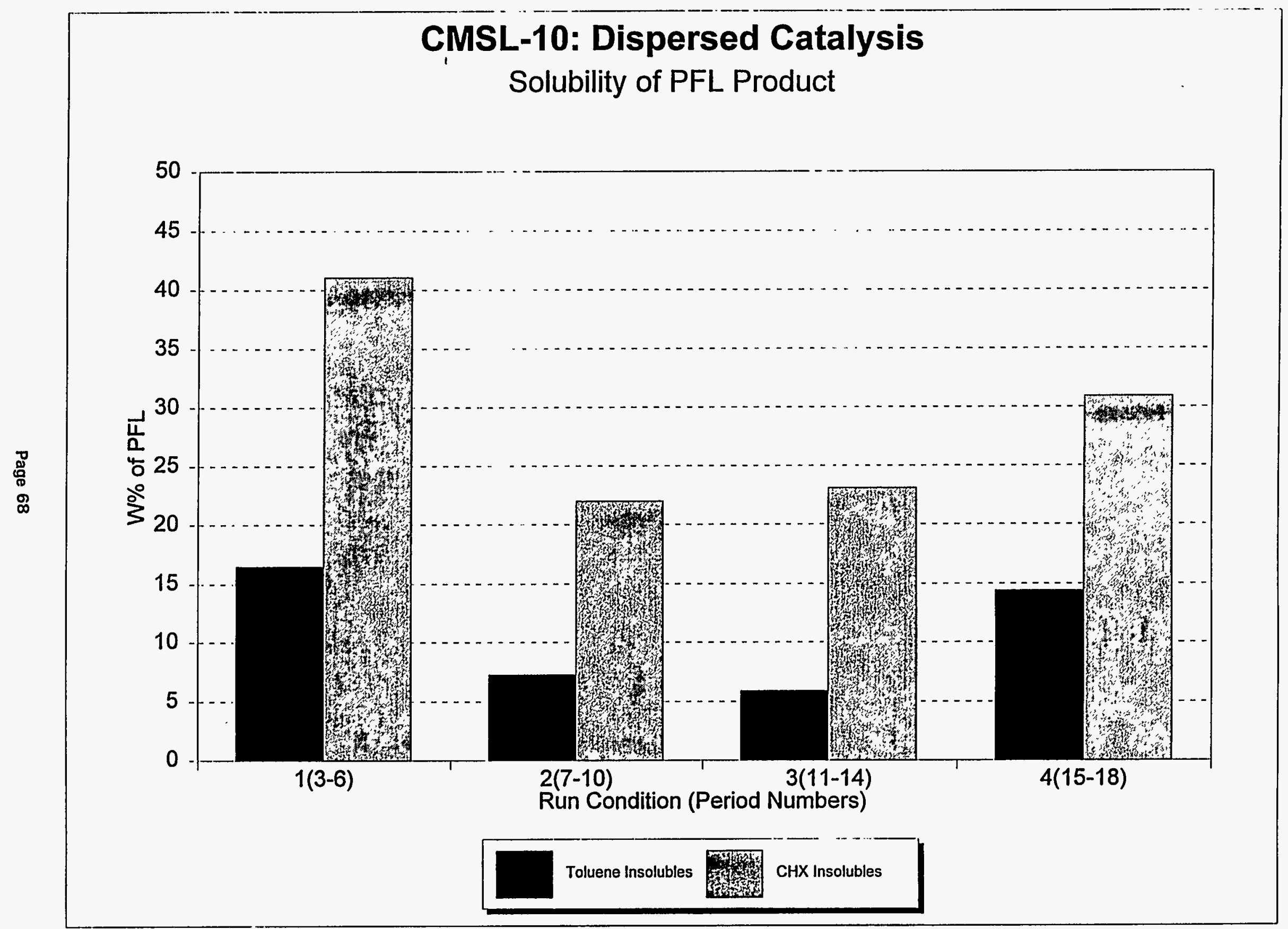


FIGURE 24

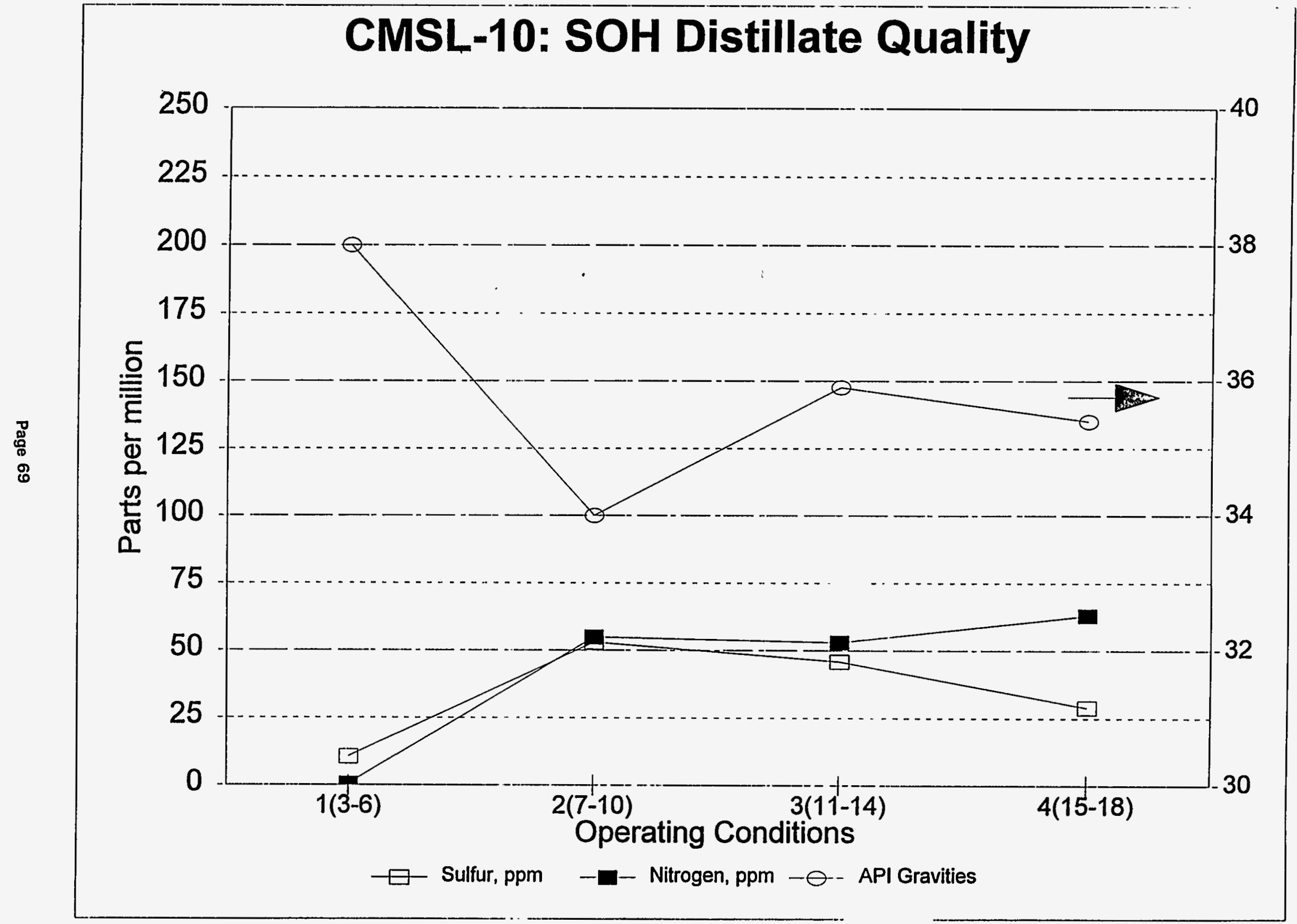




\section{TASK 4- TECHNICAL ASSESSMENT}

No technical assessment activity was conducted during this quarter. 


\section{TASK 5- PROJECT MANAGEMENT}

A paper for was prepared during this quarter for the DOE Contractors' Review Meeting to be held in Pittsburgh, PA, and for the CFFLS Ninth Annual Meeting to be held in Pipestem, WV, both during August 1995. 